\title{
Aspectos de la evolución reciente de los mercados laborales de América Latina y el Caribe
}

\author{
Jürgen Weller
}

En este artículo se presentan tres hechos estilizados que caracterizaron a la evolución de los mercados laborales de América Latina y el Caribe en el período comprendido entre 2003 y 2012 y que representan quiebres de tendencia respecto de la evolución previa. Se argumenta que estos cambios se relacionan con el contexto económico-productivo y el marco político-institucional. Se muestra cómo la magnitud y las pautas del crecimiento económico incidieron en las características de la generación de empleo, subrayando la repercusión de cambios entre y dentro de los sectores económicos y de los segmentos de diferentes niveles de productividad. Asimismo, se enfatiza el aporte de los cambios en la institucionalidad laboral a la evolución de los indicadores laborales. Finalmente, se destacan los últimos avances y las debilidades persistentes en el desempeño laboral, y también algunos factores que constituyen riesgos para la continuidad de las recientes tendencias laborales favorables. de Desarrollo Económico de la Comisión Económica para América Latina y el Caribe (CEPAL). jurgen. weller@cepal.org 


\section{I}

\section{Introducción}

En la década de 2000, el desempeño laboral de América Latina y el Caribe se diferenció notoriamente de los resultados registrados en las dos décadas previas. Sobre todo a partir de 2003, a nivel regional se observó un quiebre de varias tendencias registradas con anterioridad: se redujo la tasa de desempleo, mejoraron muchos indicadores de calidad del empleo en el contexto de una mayor formalidad laboral y disminuyeron las brechas salariales entre los trabajadores más y menos calificados. Estos factores contribuyeron a reducir las tasas de pobreza y los niveles de desigualdad entre los hogares observados en este período.

A esta evolución favorable contribuyeron varios factores que tuvieron diversa presencia en los países de la región, específicamente factores económico-productivos y político-institucionales.

El análisis realizado en este artículo se centra en el decenio que se inició en 2003 para analizar cómo un entorno económico-productivo más favorable ha incidido en los mercados laborales. En efecto, en contraste con lo registrado durante las dos décadas previas, durante ese decenio la economía de la región creció a tasas relativamente elevadas y sostenidas, solo interrumpidas por la crisis económica y financiera de 2008-2009¹. Además, en muchos países se abandonó el paradigma de crecimiento y desarrollo predominante en la región durante los años ochenta y noventa (centrado en la confianza en la eficacia y eficiencia superior de la regulación por medio del mercado), lo que en muchos casos se tradujo en modificaciones de las políticas laborales. Como se verá en el presente artículo, ambos factores tuvieron importantes consecuencias para la evolución de los mercados de trabajo durante este período.

En las siguientes secciones, luego de esta Introducción, se revisan las recientes transformaciones de los mercados laborales de la región y se las interpreta con el trasfondo de los cambios del entorno económicoproductivo y de la institucionalidad laboral. En la sección II

\footnotetext{
${ }^{1}$ Véase CEPAL (varios años) y, específicamente acerca del subperíodo 2003-2008, véase Kacef y López-Monti (2010).
}

se ilustran algunos hechos laborales estilizados que caracterizaron a los mercados laborales en el período reciente, y se los contrasta con el desempeño previo. En la tercera sección se presenta un esquema destinado a analizar los factores determinantes de esta evolución, justificándose el énfasis en el contexto económico y productivo y en la institucionalidad laboral. En la sección IV se analizan las características asumidas por estos factores en el decenio 2003-2012, con lo que se pretende contribuir a la comprensión de la reciente evolución de los mercados laborales. Se muestra que el crecimiento económico relativamente elevado fue el principal factor que impulsó la dinámica generación de empleo y la reducción de la tasa de desempleo regional. El moderado aumento de la productividad laboral, basado en diferentes procesos, facilitó mejoras en la calidad del empleo. A ello también contribuyó la fuerza de la demanda laboral, que permitió que gran parte de los nuevos puestos de trabajo se crearan en segmentos de productividad media y alta, lo que incidió en una favorable recomposición de la estructura del empleo. Las pautas de la demanda laboral también contribuyeron a reducir las brechas de ingresos entre personas de diferentes niveles de empleo. Finalmente, una reorientación de la institucionalidad laboral favoreció en muchos países dicha reducción de brechas, e incentivó mejoras en la calidad del empleo. En la sección V se concluye destacando los recientes avances y las debilidades persistentes en el desempeño laboral, y en ella se plantean algunos factores que implican riesgos para la continuidad de las recientes tendencias laborales favorables ${ }^{2}$.

\footnotetext{
${ }^{2}$ No se pretende un análisis de la reciente evolución de los mercados laborales en todos sus aspectos. La revisión de los hechos estilizados se concentra más bien en aquellos que mostraron una ruptura con respecto a su desempeño anterior, y se deja afuera a los indicadores en que se mantuvieron las tendencias previas. Esto se refiere, por ejemplo, a las características de la oferta laboral, donde permanecieron las tendencias demográficas, así como el incremento gradual de la participación laboral y del nivel de la educación formal. Como es obvio, estos hechos estilizados no caracterizan a la evolución de todos los países de la región, ya que cada uno de ellos cuenta con pautas específicas en los factores determinantes del desempeño laboral.
} 


\section{II}

\section{Tres hechos estilizados}

El primer hecho estilizado de la evolución de los mercados laborales en el período reciente es la reducción de la tasa de desempleo abierto de las zonas urbanas, que entre 2002 y 2012 se contrajo a nivel regional de un $11,2 \%$ a un $6,4 \%$, el menor nivel de los últimos 20 años (CEPAL/OIT, 2013) ${ }^{3}$. Con ello se revirtió la tendencia ascendente del desempleo que había caracterizado a los años noventa, cuando este bajó poco en períodos de crecimiento económico relativamente alto y subió ostensiblemente en fases de crecimiento bajo o negativo, lo que le dio el aspecto de un "serrucho ascendente" a la curva de la tasa de desempleo regional ${ }^{4}$.

${ }^{3}$ De esta manera, se volvió a los niveles de los años ochenta y setenta. Sin embargo, una comparación precisa no es posible, debido a los cambios metodológicos introducidos entretanto en muchos países.

${ }^{4}$ En su estudio sobre 19 países latinoamericanos, enfocado - con diferencias según la disponibilidad de datos- en el período de 1990 a 2007, Ball, De Roux y Hofstetter (2011) encontraron evidencia
La reducción del desempleo a partir de 2003 es el resultado de un dinámico aumento de la tasa de ocupación, como puede observarse en el gráfico 1 .

Mientras la tasa de participación reflejó la tendencia de largo plazo de un gradual incremento de la inserción de las mujeres en el mercado laboral, la tasa de ocupación registró un marcado aumento a partir de 2003, interrumpido solo en 2009 en el marco de la crisis económica y financiera global.

A partir de 2003, el mayor incremento de los niveles de empleo contribuyó, junto con las mayores remuneraciones de los ocupados, a acrecentar los ingresos laborales, que fue el principal factor de reducción de la pobreza en la región en ese período (CEPAL, 2012, pág. 50; Azevedo y otros, 2013).

para un efecto histéresis que transformó aumentos de corto plazo de las tasas de desempleo (causados por contracciones de la demanda agregada) en efectos de largo plazo.

GRÁFICO 1

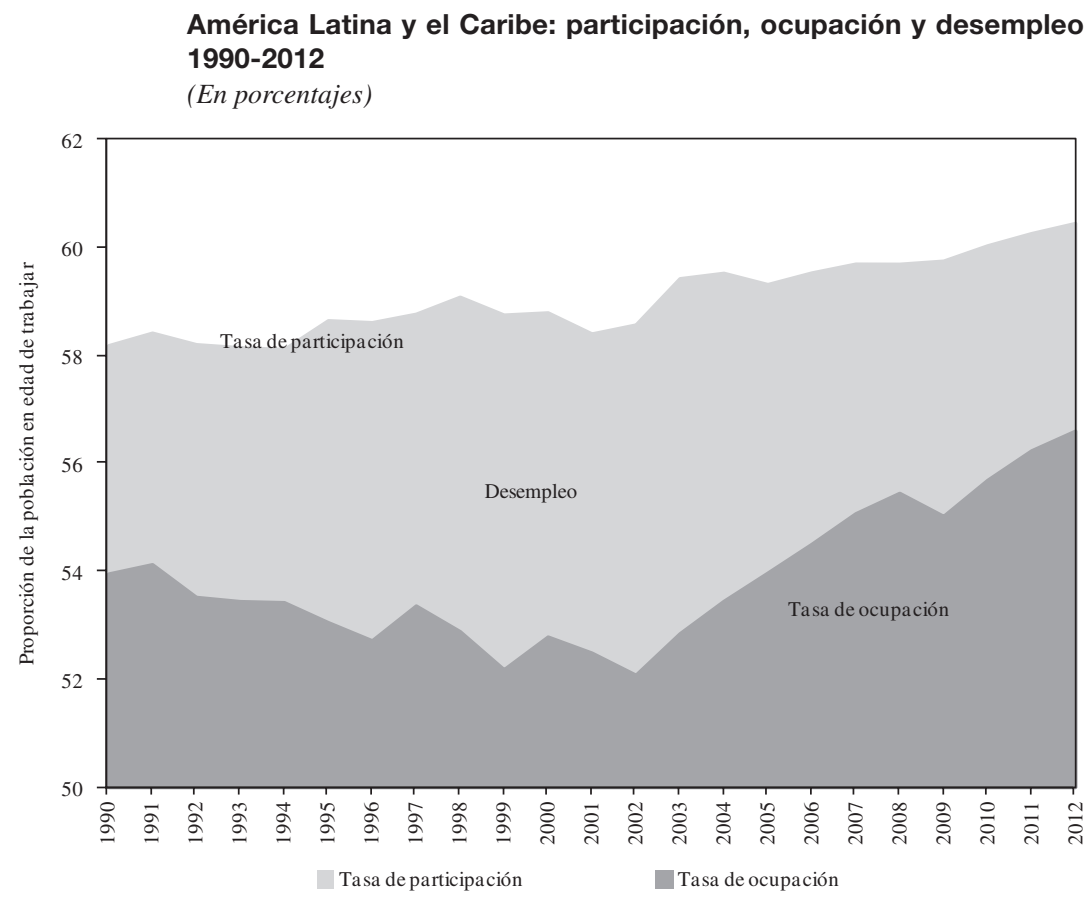

Fuente: elaboración propia sobre la base de datos oficiales de los países.

Nota: en el gráfico, el desempleo se presenta como brecha entre las tasas de participación y de ocupación, por lo que los valores no corresponden a la tasa de desempleo, la que se calcula como proporción de la fuerza de trabajo. 
El segundo hecho estilizado lo constituyen las mejoras de la calidad del empleo. Como constatan Weller y Roethlisberger (2011), durante el período reciente casi todos los indicadores de calidad mostraron mejoras, con la excepción del aumento de las relaciones laborales temporales, como reflejo de mercados de trabajo más inestables. Los asalariados suelen registrar mejores indicadores de calidad que los no asalariados, pero en el período reciente en general se observaron mejoras en la calidad del empleo respecto de ambas categorías ${ }^{5}$.

Como se constata en el documento antes citado, estas mejoras se relacionan estrechamente con procesos de formalización laboral que, en algunos países, avanzaron de manera significativa. Tal como se indica en el gráfico 2 , durante el decenio 2003-2012 en muchos países de la región el empleo formal se expandió más que en el período anterior y claramente más que el empleo en su conjunto.

El tercer hecho estilizado es la reducción de las brechas salariales, que representa un quiebre de las tendencias previas a la polarización de la estructura

5 Véase también la información sobre la cobertura diferenciada por sistemas de protección social y su actual evolución en oIT (varios años). salarial ${ }^{6}$. En la mayoría de los países, la disminución de la brecha salarial fue el factor principal para aminorar la desigualdad de ingresos a nivel de los hogares durante la década pasada. En el promedio de 15 países, alrededor de dos tercios de esta reducción obedecieron a la merma de las diferencias en los ingresos por ocupado (CEPAL, 2012, pág. 56) ${ }^{7}$. El segundo factor relevante lo constituyen los ingresos no laborales, como reflejo de la introducción y expansión de programas de ingresos focalizados en los hogares más pobres. En contraste, en la gran mayoría de los países el cambio demográfico (reducción de la brecha respecto de la tasa de dependencia entre el primer y el quinto quintil) solo aportó muy poco a la mengua de la desigualdad. En el promedio de los países, el aporte de la mayor ocupación — que fue positiva con respecto a la reducción de la pobreza - tuvo incluso un leve efecto negativo al aumentar la proporción de adultos ocupados tanto o más en el quintil de mayores ingresos que en el más pobre.

\footnotetext{
6 Sobre la reducción de la brecha salarial véanse, por ejemplo, Gasparini y otros (2011); López-Calva y Lustig (2010), y Keifman y Maurizio (2012).

7 Véase también al respecto Azevedo, Inchauste y Sanfelice (2013).
}

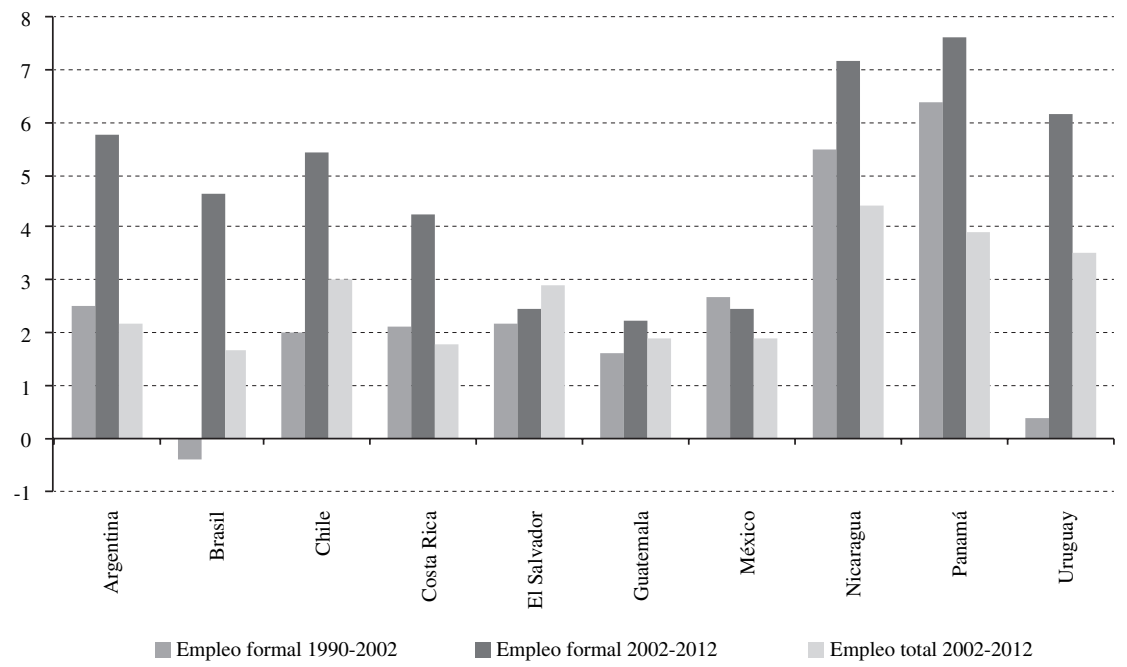

Fuente: elaboración propia sobre la base de datos oficiales de los países.

Notas: los datos sobre el empleo formal se refieren a la evolución de la cotización o afiliación a algún sistema de protección social contributivo, con la excepción del Brasil (registro de empleo formal). Los datos correspondientes a la Argentina y el Uruguay sobre el empleo total se refieren al empleo urbano. Los datos de Guatemala y Nicaragua sobre el empleo total aluden a los períodos 2002-2011 y 2003-2010, respectivamente. En el primer período, los datos del empleo formal corresponden al período 1991-2002 para Panamá; 1994-2002 para Chile, México y Nicaragua; 1995-2002 para la Argentina, y 1998-2002 para El Salvador. 


\section{III}

\section{Aspectos conceptuales}

Los principales determinantes para la generación de empleo y sus características son el contexto económico y productivo y la institucionalidad laboral ${ }^{8}$. En el gráfico 3 se resumen las principales relaciones a este respecto.

El contexto productivo se expresa, primero, en el crecimiento económico que se basa, en buena medida, en una mayor incorporación de los factores de producción, entre ellos, el trabajo. El crecimiento no solo incide en la magnitud de la generación de empleo, sino también - a través de sus características (composición sectorial, incorporación de tecnologías, entre otras)en una demanda laboral diferenciada de calificaciones, habilidades, conocimientos y otros, e influye, por lo tanto, en las condiciones laborales relativas de diferentes grupos de trabajadores.

En segundo lugar, y obviamente en relación con el aspecto anterior, el contexto económico-productivo se expresa también en la productividad laboral media de una economía, la que influye en la capacidad de mejorar la calidad de los empleos, dado que es un factor determinante del margen de beneficios que se

${ }^{8}$ Aquí se deja a un lado la estrecha correlación de largo plazo entre el nivel del empleo y la evolución demográfíca (magnitud y crecimiento de la población en edad de trabajar), modificada por la tendencia ascendente de la participación laboral causada por la creciente incorporación de las mujeres al mercado laboral. Véase al respecto Weller y Kaldewei (2013, págs. 31 y 32). otorgan a los trabajadores. A este respecto, la principal relación existe entre la productividad laboral y el nivel salarial. Al comparar entre países esta relación suele ser estrecha, si bien las ganancias de dicha productividad no se transfieren de manera automática a aumentos proporcionales de los salarios, lo que recientemente se ha reflejado en el empeoramiento de la distribución funcional de los ingresos ${ }^{9}$. Pero también aspectos no salariales de la calidad del empleo tienden a beneficiarse de una mayor productividad, puesto que los componentes de dicha calidad usualmente generan costos, y la capacidad de las economías de cubrir estos costos depende de los recursos disponibles. Por consiguiente, una alta productividad tiende a favorecer de manera directa la existencia de empleos de buena calidad, mientras que una baja productividad suele conllevar procesos de exclusión del empleo productivo ${ }^{10}$.

\footnotetext{
${ }^{9}$ En CEPAL/OIT (2012) se muestra tanto la elevada correlación entre la productividad laboral y los salarios medios, como la reciente tendencia de la reducción de los salarios como proporción del PIB.

10 Weller y Roethlisberger (2011, págs. 54-58) muestran algunas correlaciones entre el PIB per cápita (como variable indirecta para la productividad laboral) y varios indicadores de la calidad del empleo. Las relaciones positivas más evidentes se observaron respecto de las cotizaciones a los sistemas de seguridad social (pensiones y salud), los contratos y, en menor grado, el aguinaldo y las vacaciones. Otros indicadores (sindicalización, jornada excesiva, capacitación) registran una elevada dispersión, lo que indica la importancia de otros factores
}

GRÁFICO 3

Factores determinantes de la generación de empleo y su calidad

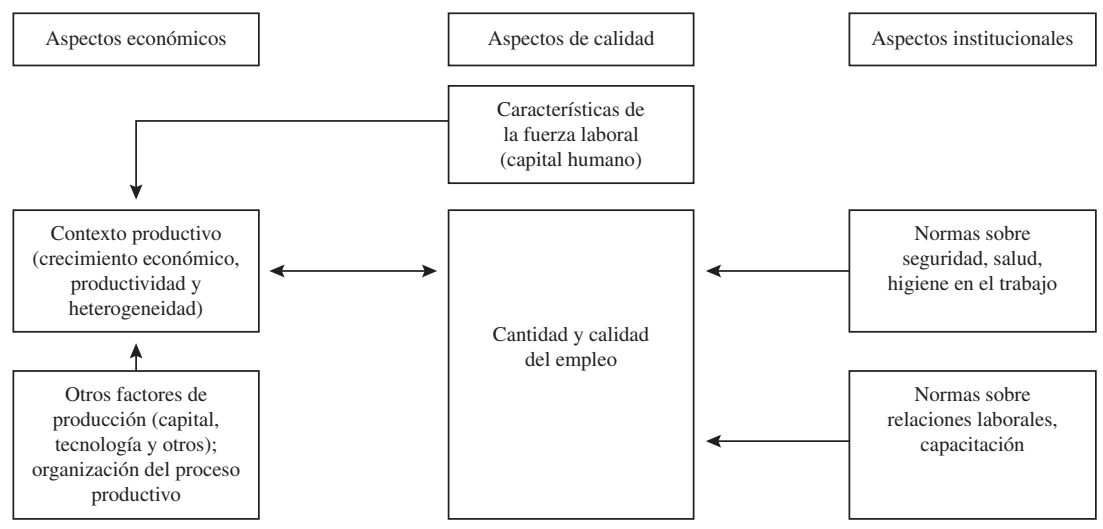

Fuente: elaboración propia sobre la base de Jürgen Weller y Claudia Roethlisberger, "La calidad del empleo en América Latina", serie Macroeconomía del Desarrollo, № 110 (LC/L.3320-P), Santiago de Chile, Comisión Económica para América Latina y el Caribe (CEPAL), 2011. Publicación de las Naciones Unidas, $\mathrm{N}^{\circ}$ de venta: S.11.II.G.39. 
El crecimiento de la productividad laboral a nivel agregado responde a dos dinámicas distintas, aunque vinculadas. Por una parte, el desarrollo económico se relaciona estrechamente con procesos de cambio estructural que implican la reasignación de recursos desde sectores de baja productividad - típicamente generadores de empleos de baja calidad - hacia sectores de productividad intermedia y alta (mejora de la productividad debido a cambios intersectoriales). Por otra, la productividad de las diferentes actividades puede aumentar gracias a una mayor intensidad de capital físico, humano o de ambos, a cambios tecnológicos, a un uso más eficiente de los recursos asignados a ellas, así como al cierre de empresas poco productivas y la formación de nuevas firmas que llegan a ser más productivas (mejora de la productividad derivada de cambios intrasectoriales). El peso relativo de ambos procesos varía típicamente con el avance del desarrollo económico, disminuyendo gradualmente el aporte del cambio estructural (Rodrik, 2013).

Sin embargo, y en tercer lugar, en contextos productivos altamente heterogéneos, no basta con identificar la tasa de crecimiento económico y la evolución de la productividad media como variables que reflejan la importancia del contexto productivo para la generación del empleo y sus características.

Con frecuencia se argumenta en contra de la hipótesis de la segmentación, planteando que una significativa proporción del empleo informal es voluntaria, como resultado de cálculos de costo-beneficio de empresas y trabajadores, y específicamente para aprovechar los beneficios sociales también accesibles crecientemente desde la informalidad, sin tener que asumir los costos relacionados con la formalidad. Asimismo, en estudios sobre los flujos de trabajadores dentro de este mercado se advierte un grado de movilidad entre los diferentes segmentos que contradiría a una hipótesis de mercados segmentados (Perry y otros, 2007; Bosch, Cobacho y Pagés, 2012). Sin negar el papel de los razonamientos sobre los costos y beneficios tanto de la formalidad como de la informalidad, hay que insistir en que existen razones teóricas y empíricas para analizar estos mercados como

más allá del PIB per cápita y, relacionada con él, la productividad media, específicamente la importancia de la institucionalidad laboral, tema que se revisará más adelante. Cabe subrayar que la relación entre la productividad laboral y la calidad del empleo es bidireccional, como se ha observado históricamente, por ejemplo, con el abreviamiento de la jornada laboral. En esta misma dirección, la teoría de los salarios de eficiencia conceptualiza la incidencia de mejores salarios en una productividad más elevada. Véase al respecto Akerlof y Yellen (1986). segmentados (Fields, 2004; Ocampo, Rada y Taylor, 2009; Infante, 2011):

- La estructura productiva de la región se caracteriza por una marcada heterogeneidad, expresada especialmente en elevadas brechas de productividad inter e intrasectoriales.

- La debilidad de la demanda laboral de los segmentos con alta y media productividad incide en que, además de los empleos surgidos sobre todo en respuesta a esta demanda, se generen puestos de trabajo que responden particularmente a la presión de la oferta laboral, reflejando las necesidades de ingresos de los hogares correspondientes ${ }^{11}$.

De todas maneras, los diferentes enfoques en la literatura sobre la segmentación del mercado laboral han avanzado en el sentido de reconocer la heterogeneidad del sector informal mismo ${ }^{12}$. Mientras que en cierto enfoque los trabajadores informales se diferencian entre "excluidos" y "voluntarios", desde una perspectiva productiva se distingue un subsegmento con cierto potencial de acumulación de otro cuyos ingresos están atados a niveles de subsistencia. De modo correspondiente, habría un subsegmento de comportamiento contracíclico — que crece en aquellas fases del ciclo caracterizadas por una baja demanda laboral de los segmentos de productividad media y alta- y otro con una dinámica procíclica que se expande debido a las oportunidades de ingresos en el contexto de una economía en crecimiento.

Además, la existencia simultánea de segmentos del mercado laboral —cuya evolución se determina sobre todo por la demanda y la oferta laboral, respectivamente- se expresa en la manera en que este mercado se ajusta al ciclo económico. De manera específica, la presencia de un gran segmento del mercado de trabajo, que obedece a las dinámicas provenientes de la oferta laboral, incide en que la productividad laboral se comporte de manera altamente procíclica (CEPAL/OIT, 2012).

En resumen, el nivel de la informalidad y su composición dependen de dos factores principales: la estructura productiva — representada por el nivel del producto per cápita y las brechas de productividad

\footnotetext{
11 En este artículo se denomina "segmento" al conjunto de aquellas partes de las diferentes ramas de actividad o sectores que comparten niveles similares de productividad, diferenciando de manera simplificada segmentos de baja productividad en comparación con los de media y alta productividad. El cambio de la importancia relativa de ambos segmentos a lo largo del ciclo económico también es reconocido por Perry y otros (2007).

12 Véanse, por ejemplo, Tokman (1987); Fields (2004) y Perry y otros (2007).
} 
entre los distintos segmentos-y los aspectos jurídicoinstitucionales que determinan los costos y beneficios tanto de la formalidad como de la informalidad ${ }^{13}$.

La existencia de mercados segmentados con grandes brechas de productividad repercute en que cambios en la composición de la estructura ocupacional —especialmente en el peso relativo de los segmentos de mayor o menor productividad - influyen en los promedios agregados de ella y en los ingresos laborales. Además, la segmentación del mercado de trabajo también tiene consecuencias distributivas. Si bien en el debate teórico hay discrepancias acerca de si los segmentos de baja productividad deberían ser modelados con un producto marginal cercano a cero o con uno positivo y decreciente (Fields, 2004), un incremento del número de personas ocupadas en estos segmentos bajaría los ingresos medios y ampliaría la brecha de ingresos con los segmentos de productividad más elevada. En contraste, una reducción del número de trabajadores en los segmentos de bajo rendimiento incrementaría los ingresos medios y disminuiría la brecha con respecto a los segmentos de productividad media o más elevada. Una implicancia de esta situación es que en países con un conjunto de segmentos de baja productividad relativamente más grande, la brecha de ingresos entre los segmentos de diferentes niveles de productividad debería ser mayor que en países con un conjunto de segmentos de baja productividad relativamente más pequeño: en el primer grupo de países, el ingreso medio de los segmentos de baja productividad tiende a ser más reducido a causa de la mayor presencia de empleos generados por la presión de la oferta, lo que aumenta la brecha entre este ingreso medio y el de los segmentos de productividad media y alta ${ }^{14}$.

Finalmente, la institucionalidad laboral — basada en la legislación laboral o en la negociación colectivainfluye en las características del empleo, particularmente en aspectos de su calidad y en las brechas que existen

\footnotetext{
${ }^{13}$ Se podrían añadir aspectos secundarios, como la falta de información sobre las empresas y trabajadores informales con respecto a estos costos y beneficios.

${ }^{14}$ Esto se muestra para América Latina en Weller (2012, pág. 35).
}

al respecto para diferentes grupos de trabajadores (por ejemplo, por medio de políticas de formalización o del salario mínimo). Esta institucionalidad tiene un doble objetivo (CEPAL, 2010, pág. 173): i) contribuir al funcionamiento eficiente del mercado laboral (incorporando cada vez más a la fuerza laboral en empleos productivos), estimular aumentos de la productividad (lo que incluye la distribución efectiva de los frutos correspondientes) y diseñar mecanismos que permitan ajustes adecuados a los vaivenes del ciclo económico; y ii) favorecer la protección de los trabajadores como actores estructuralmente más débiles, sobre todo de los grupos vulnerables con problemas específicos en la inserción laboral productiva.

Con tal objeto, la legislación laboral y la negociación colectiva afectan al proceso de determinación de los salarios y otros beneficios, los contratos, la protección social, y la capacitación, entre otros aspectos. A la vez, las normas de higiene y seguridad en el trabajo y sobre su organización (ritmo, pausas y otros) influyen en las condiciones laborales.

Por otra parte, la capacidad de cumplimiento de las empresas, la cobertura y eficiencia de la inspección del trabajo y de la justicia laboral, así como la capacidad de control y presión de los trabajadores determinan hasta qué grado los aspectos de calidad previstos por la legislación y la negociación se hacen realidad (Bensusán, 2008).

Cabe señalar que las instituciones solo pueden cumplir con sus objetivos de manera sostenible si están doblemente insertas (Berg y Kucera, 2008, pág. 27): primero, responderían a las normas sociales históricamente surgidas en un país específico, de manera que varían entre los países. Por lo tanto, no sorprende que en la literatura teórica se esté considerando cada vez más la posibilidad de pasar de modelos que suponen la existencia de una sola configuración óptima de regulaciones, a otros en que se plantea la existencia de dos o más configuraciones institucionales que pueden generar resultados similares (Eichhorst, Feil y Braun, 2008). Segundo, tomarían en cuenta el contexto productivo, de modo que en un país dado deberían variar a lo largo del tiempo ante cambios sociales y políticos de ese contexto. 


\section{IV}

\section{Cambios en los factores determinantes y sus vínculos con los hechos estilizados}

En esta sección se indaga cómo los cambios en el contexto económico-productivo y en la institucionalidad laboral pueden haber incidido durante el período iniciado en 2003 en los hechos estilizados resumidos en la segunda sección.

\section{La estructura económico-productiva}

a) El crecimiento económico y el empleo agregado El crecimiento económico y sus características fueron el principal factor explicativo del aumento del nivel del empleo y, por lo tanto, de la reducción de la tasa de desempleo. La evolución de las economías de América Latina y el Caribe en el período iniciado en 2003 se diferenció nítidamente de la ocurrida en las décadas previas. Gracias a la dinámica y las nuevas pautas del crecimiento de la economía mundial, los precios de los principales bienes básicos de exportación de la región registraron fuertes incrementos, lo que redundó en mejoras de los términos de intercambio que favorecieron a los países productores tanto de hidrocarburos, como de minerales y productos agrícolas ${ }^{15}$. Este contexto influyó decisivamente en un crecimiento económico regional que superó el desempeño de las décadas anteriores. Las autoridades económicas aprovecharon esta coyuntura para enfrentar vulnerabilidades, reduciendo la deuda pública $\mathrm{y}$, especialmente, externa e incrementando las reservas monetarias internacionales. La combinación de mayores perspectivas de crecimiento y vulnerabilidades reducidas contribuyó a mejorar las condiciones de financiamiento externo, sobre todo en el contexto de elevados niveles de liquidez en los mercados globales (CEPAL, varios años).

En este contexto, el crecimiento económico de la región aumentó un 2,7\% anual entre 1990 y 2002 y un $3,8 \%$ de 2003 a 2012, pese al recio impacto de la crisis económica y financiera global en 2008-2009 ${ }^{16}$. Conviene destacar que las pautas de crecimiento se diferenciaron a

\footnotetext{
15 Las diferencias en la composición de las canastas exportadora e importadora obviamente se vieron reflejadas en una evolución muy variada de los términos de intercambio de los países de la región.

16 Entre 2003 y 2008 la región creció anualmente un 4,5\%, en tanto que de 2010 a 2012 la expansión anual fue de un 4,4\% y en 2009 la economía regional se contrajo un $1,6 \%$.
}

lo largo del último decenio, ya que el subperíodo 20032008 se caracterizó por un dinámico incremento de las exportaciones (del 16,9\% del producto interno bruto (PIB) en el promedio del período 1990-2002 al 22,7\% en el promedio del lapso 2003-2008, a precios constantes). Mientras que en el subperíodo 2009-2012 fueron sobre todo el consumo de los hogares y la formación bruta de capital fijo los que impulsaron la demanda agregada (con aumentos entre el promedio de 2003-2008 y 2009-2012 del 63,0\% al 65,0\% en el caso del consumo de hogares, y del $19,1 \%$ al $21,2 \%$ en el de la formación bruta de capital fijo) ${ }^{17}$. En términos sectoriales, el crecimiento se concentró en los diferentes rubros del sector terciario, pauta que se profundizó en el período comprendido entre 2009 y $2012^{18}$.

Como se observa en el gráfico 4 , el engrosamiento de la tasa de ocupación, constatado previamente (véase el gráfico 1), se explica en gran medida por estas tasas de crecimiento económico más elevadas.

En efecto, con la excepción de 2009, en todos los años entre 2003 y 2012 la tasa de ocupación urbana se incrementó en 0,4 puntos porcentuales o más.

La relación entre el crecimiento económico y la variación de la tasa de ocupación indica, además, un aumento de la intensidad laboral del crecimiento. Los datos presentados en el gráfico 4 indican que durante los años noventa, a nivel regional, un crecimiento económico de un 3\% se relacionó con una baja de la tasa de ocupación urbana regional de 0,1 punto porcentual, mientras que en el período iniciado en 2003 esta expansión del producto incidió en un acrecentamiento de esta tasa de más de 0,3 puntos (CEPAL, 2014b). La reducida intensidad del trabajo en el crecimiento durante los años noventa ha sido relacionada, entre otras causas, con las reformas laborales de la época (Weller, 2000; BID, 2003). Este efecto puede haberse atenuado posteriormente, y en el período siguiente pocas reformas liberalizadoras

\footnotetext{
17 Cálculo propio sobre la base de datos de la Comisión Económica para América Latina y el Caribe (CEPAL).

${ }^{18}$ En conjunto, estas ramas de actividad aumentaron su participación en el PIB del 54,5\% en el promedio 1990-2002 al 55,3\% en el de 20032008, y al 56,8\% en el correspondiente a 2009-2012.
} 


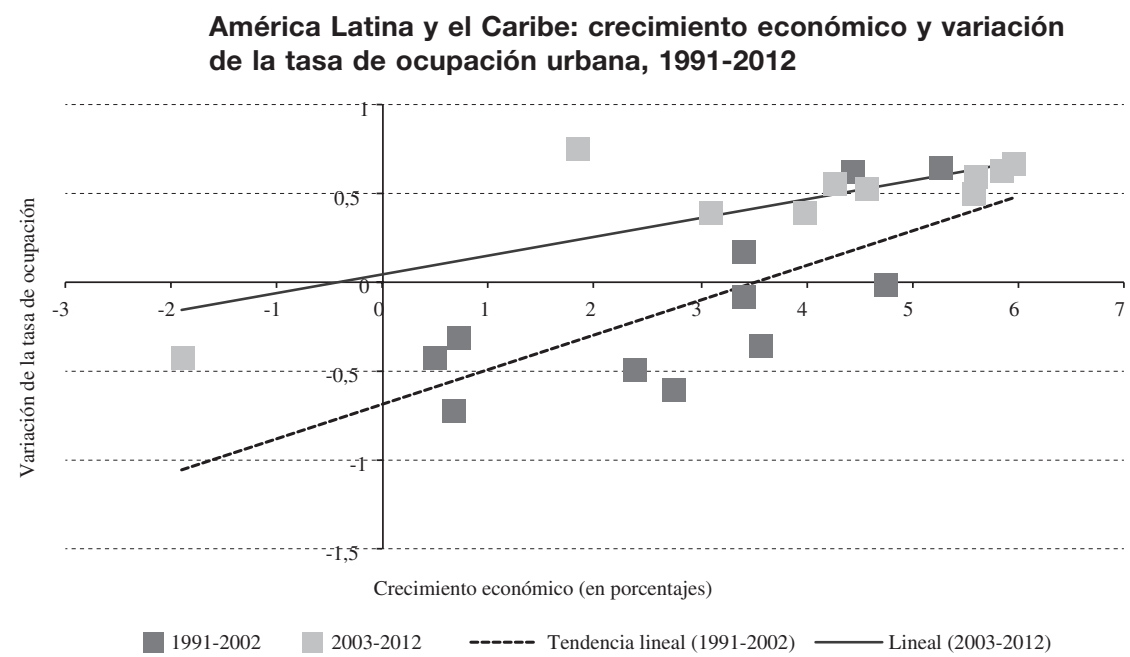

Fuente: elaboración propia sobre la base de datos de la Comisión Económica para América Latina y el Caribe (CEPAL).

de gran envergadura fueron implementadas (CEPAL, 2014b). De todas maneras, la baja intensidad laboral en el crecimiento regional durante los años noventa se debió principalmente al desempeño de pocos países (Argentina y Brasil), y en la mayoría de los países de la región no se puede hablar de un fenómeno generalizado de "crecimiento sin empleo", ya que muchos de ellos se caracterizaron en este período por un "empleo sin crecimiento" (Pagés, Pierre y Scarpetta, 2009), reflejo de la presión de la oferta laboral en el contexto de un bajo y volátil crecimiento económico.

En resumen, en comparación con el período anterior, en el decenio 2003-2012 el mayor crecimiento económico $\mathrm{y}$, además, la más elevada intensidad del factor trabajo en este proceso generaron significativos incrementos de la tasa de ocupación. Dado que el aumento de la tasa de participación no se apartó de su tendencia de largo plazo, esta mayor generación de empleo se tradujo directamente en una ostensible reducción de la tasa de desempleo.

\section{b) La evolución de la productividad laboral}

Como se ha planteado anteriormente, la evolución de la productividad laboral es un determinante clave en las mejoras de la calidad del empleo tanto salarial como no salarial. En el decenio 2003-2012, el entorno económico más favorable se expresó en un aumento de la productividad laboral media, después de su retroceso durante los años ochenta y su estancamiento en los años noventa (Weller y Kaldewei, 2013) ${ }^{19}$.

19 Sin embargo, el aumento de la productividad laboral media de un $1,6 \%$ entre 2002 y 2012 fue modesto en comparación con
Según se precisó previamente, este aumento puede provenir de transformaciones internas de los sectores económicos, de la reasignación de recursos o, específicamente, de la fuerza de trabajo entre sectores (cambio estructural). Respecto de los años ochenta, la CEPAL (2007) ha encontrado una pronunciada caída de la productividad laboral media, causada por efectos intrasectoriales con efectos intersectoriales levemente positivos, mientras que en relación con el período 1991 a 2003 se halló —en el promedio simple de nueve países - un leve incremento de la productividad laboral media, con modestos aportes positivos de ambos componentes. En contraste, McMillan y Rodrik (2011) encontraron con respecto al período comprendido entre 1990 y 2005, también para nueve países, una fuerte contribución positiva de los cambios intrasectoriales, contrarrestada parcialmente por un impacto negativo del cambio intersectorial ${ }^{20}$.

En el cuadro 1 se presentan los resultados de un ejercicio para los períodos 1990-2002 y 2003-2011/2012, respecto de los cuales se utilizó la misma metodología aplicada por McMillan y Rodrik (2011) a 23 países

\footnotetext{
algunas otras regiones. Debido sobre todo al dinámico incremento de la productividad en Asia oriental, al año 2012 casi se eliminó la brecha favorable que la región mantuvo históricamente con respecto al promedio mundial, el que se expandió anualmente en este período en un 2,2\% (cálculo propio sobre la base de datos de Indicadores Clave del Mercado de Trabajo (KILM por sus siglas en inglés), octava edición (OIT, 2013)).

${ }^{20}$ Otros estudios recientes, con una descomposición de la evolución de la productividad laboral para diferentes períodos, son los de Ocampo, Rada y Taylor (2009) y Ros (2011).
} 
CUADRO 1

América Latina y el Caribe: variación de la productividad laboral media y contribuciones de los cambios inter e intrasectoriales, 1990-2002 y 2003-2011/2012

\begin{tabular}{|c|c|c|c|c|c|c|c|}
\hline & \multirow[b]{2}{*}{ Períodos } & \multicolumn{3}{|c|}{ 1990-2002 } & \multicolumn{3}{|c|}{$2002-2011 / 2012$} \\
\hline & & $\begin{array}{l}\text { Variación } \\
\text { de la } \\
\text { productividad } \\
\text { por año }\end{array}$ & $\begin{array}{l}\text { Contribución } \\
\text { intersectorial }\end{array}$ & $\begin{array}{l}\text { Contribución } \\
\text { intrasectorial }\end{array}$ & $\begin{array}{l}\text { Variación } \\
\text { de la } \\
\text { productividad } \\
\text { por año }\end{array}$ & $\begin{array}{l}\text { Contribución } \\
\text { intersectorial }\end{array}$ & $\begin{array}{l}\text { Contribución } \\
\text { intrasectorial }\end{array}$ \\
\hline Argentina urbano ${ }^{\mathrm{a}}$ & $1990-2002$ у 2002-2012 & 1,0 & 0,8 & 0,2 & 3,9 & 0,2 & 3,7 \\
\hline Las Bahamas & $1989-2003$ у $2003-2011$ & 0,0 & 0,4 & $-0,4$ & 0,2 & 0,3 & $-0,1$ \\
\hline Barbados & $1990-2002$ у 2002-2012 & $-1,1$ & $-0,7$ & $-0,4$ & 1,8 & 0,3 & 1,5 \\
\hline $\begin{array}{l}\text { Bolivia (Estado } \\
\text { Plurinacional de) }\end{array}$ & $1996-2002$ у 2002-2009 & 1,5 & 0,1 & 1,4 & 0,2 & 1,4 & $-1,2$ \\
\hline Brasil & $1990-2002$ y $2002-2011$ & $-0,4$ & 0,0 & $-0,4$ & 1,9 & 0,7 & 1,2 \\
\hline Chile & $1990-2002$ у 2002-2012 & 3,4 & $-0,2$ & 3,6 & 1,4 & 0,5 & 0,9 \\
\hline Colombia & $1991-2000$ y 2002-2012 & 1,0 & $-0,3$ & 1,3 & 1,7 & 0,8 & 0,9 \\
\hline Costa Rica & $1990-2002$ у 2002-2012 & 0,7 & 0,3 & 0,4 & 2,3 & 0,1 & 2,2 \\
\hline Ecuador & $1990-2001$ у 2002-2012 & $-0,7$ & $-0,1$ & $-0,6$ & 3,5 & 0,8 & 2,6 \\
\hline El Salvador & $1992-2002$ у 2002-2012 & 1,4 & 1,3 & 0,1 & 0,3 & 0,1 & 0,3 \\
\hline Guatemala & $1989-2002$ у 2002-2011 & $-0,3$ & $-0,7$ & 0,5 & 1,8 & 2,0 & $-0,2$ \\
\hline Honduras & $1990-2002$ у 2002-2012 & $-0,4$ & 0,5 & $-0,9$ & 1,7 & 0,2 & 1,6 \\
\hline Jamaica & $1992-2002$ у 2002-2012 & 0,0 & 0,2 & $-0,2$ & $-0,2$ & 0,3 & $-0,5$ \\
\hline México & 1991-2002 y2002-2012 & 0,3 & 0,9 & $-0,5$ & 0,8 & 1,1 & $-0,3$ \\
\hline Nicaragua & $1990-2003$ у $2003-2010$ & $-1,0$ & 0,5 & $-1,5$ & $-0,7$ & $-0,1$ & $-0,6$ \\
\hline Panamá & $1991-2002$ у 2002-2012 & 0,2 & 0,9 & $-0,8$ & 4,8 & 0,3 & 4,5 \\
\hline Paraguay & $1997-2002$ у 2002-2011 & $-2,6$ & $-0,6$ & $-2,0$ & 0,5 & 0,2 & 0,3 \\
\hline Perú & $1994-2002$ у 2002-2011 & $-1,7$ & $-0,4$ & $-1,2$ & 4,0 & 1,7 & 2,3 \\
\hline $\begin{array}{l}\text { República } \\
\text { Dominicana }\end{array}$ & $1991-2002$ у 2002-2012 & 2,9 & 0,1 & 2,8 & 1,8 & $-0,1$ & 1,9 \\
\hline Santa Lucía & $1994-2002$ у 2002-2007 & $-0,6$ & $-0,3$ & $-0,3$ & $-0,2$ & 1,1 & $-1,2$ \\
\hline Trinidad y Tabago & $1990-2002$ у 2002-2012 & 1,0 & 0,4 & 0,6 & 3,2 & 0,4 & 2,8 \\
\hline Uruguay urbano $^{\mathrm{a}}$ & $1990-2002$ у 2006-2011 & 1,8 & 0,9 & 0,9 & 4,2 & 0,7 & 3,4 \\
\hline $\begin{array}{l}\text { Venezuela (República } \\
\text { Bolivariana de) }\end{array}$ & $1990-2002$ у 2002-2012 & $-2,9$ & $-1,6$ & $-1,3$ & 1,5 & 1,7 & $-0,2$ \\
\hline $\begin{array}{l}\text { América Latina y el } \\
\text { Caribe }^{b}\end{array}$ & & 0,2 & 0,1 & 0,1 & 1,8 & 0,6 & 1,1 \\
\hline $\begin{array}{l}\text { Subregión norte de } \\
\text { América Latina }^{b}\end{array}$ & & 0,5 & 0,5 & 0,0 & 1,6 & 0,4 & 1,2 \\
\hline $\begin{array}{l}\text { Subregión sur de } \\
\text { América Latina }^{b}\end{array}$ & & 0,1 & $-0,1$ & 0,2 & 2,3 & 0,9 & 1,4 \\
\hline El Caribe ${ }^{b}$ & & $-0,1$ & 0,0 & $-0,1$ & 1,0 & 0,5 & 0,5 \\
\hline
\end{tabular}

Fuente: elaboración propia sobre la base de Jürgen Weller y Cornelia Kaldewei, "Empleo, crecimiento sostenible e igualdad", serie Macroeconomía del Desarrollo, $\mathrm{N}^{\circ} 145$ (LC/L.3743), Santiago de Chile, Comisión Económica para América Latina y el Caribe (CEPAL), 2013; y datos oficiales de los países y la Comisión Económica para América Latina y el Caribe (CEPAL).

Notas: las tasas de las contribuciones inter e intrasectoriales no necesariamente suman la variación de la productividad por el redondeo de las cifras. El total se refiere a la suma del valor agregado de las ramas de actividad. El cálculo se realizó a precios en dólares constantes de 1995 para 1990-2002 y en dólares constantes de 2005 para 2002-2011/2012.

La subregión norte corresponde a los países de México y Panamá, más la República Dominicana; la subregión sur corresponde a los países latinoamericanos al sur de Panamá.

a Los datos de la Argentina (31 aglomerados urbanos) y (en el período 1990-2002) del Uruguay (total urbano) son solo indicativos, pues a falta de datos del empleo a nivel nacional, se combinó la información del crecimiento del producto no agropecuario con los datos del empleo a nivel urbano.

b Promedio simple. 
de América Latina y el Caribe, de acuerdo con la descomposición siguiente:

$$
\Delta Y_{t}=\sum_{i=1}^{n} \Theta_{i, t-k} \Delta y_{i, t}+\sum_{i=1}^{n} y_{i, t} \Delta \Theta_{i, t}
$$

donde $Y_{t}$ e $y_{i, t}$ representan el nivel de la productividad para la economía en su conjunto y a nivel del sector i, respectivamente, mientras que $\Theta_{i, t}$ es la participación del sector i en el empleo. $\Delta$ representa el cambio de la productividad o de la proporción del empleo, según sea el caso. El primer término al lado derecho es la suma de las variaciones de la productividad de los diferentes sectores, ponderadas por su participación en el empleo en el inicio del período de análisis. Este término representa los cambios de la productividad dentro de los sectores. El segundo término representa la contribución del cambio estructural a la variación total de la productividad, calculado como la suma de los cambios sectoriales en la participación en el empleo total, ponderado por las productividades correspondientes ${ }^{21}$.

El resultado de este cálculo muestra el aporte de los procesos intrasectoriales y del cambio estructural a la variación de la productividad laboral agregada, en dólares constantes de 1995 para el primer subperíodo y de 2005 para el segundo. A fin de compatibilizar los resultados de los países individualmente, y tomando en cuenta que cada uno los períodos de análisis tiene una duración diferente, se han calculado las tasas de crecimiento anual de la productividad laboral para todos los países y se han transformado las contribuciones de los cambios intra e intersectoriales en contribuciones a dichas tasas de crecimiento.

Nuevamente se observa que el crecimiento de la productividad laboral media se aceleró en el segundo período en comparación con los aumentos mínimos del primero. En el promedio regional, entre 1990 y 2002 ni los cambios intrasectoriales ni el cambio estructural contribuyeron a mejoras al respecto, mientras que estos aportes fueron positivos en el segundo período, representando el cambio estructural aproximadamente un tercio del crecimiento de la productividad laboral agregada, y los cambios intrasectoriales los dos tercios restantes. De todas maneras, en ambos períodos se observan grandes diferencias entre los países y subregiones. En el primer período destacó el aporte de los cambios

${ }^{21}$ De esta manera, si un sector pierde participación en la estructura de empleo en beneficio de un sector de mayor productividad media, la productividad agregada aumenta, y viceversa. intersectoriales en la subregión norte, posiblemente a causa de la expansión de la maquila y la masiva emigración, sobre todo hacia los Estados Unidos de América. En el segundo período, la subregión sur mostró los mejores resultados en ambos componentes del crecimiento de la productividad. En los dos períodos, el Caribe registró los resultados más débiles.

La productividad laboral moderadamente creciente facilitó incrementos de los salarios reales. Según la información procedente de las encuestas de hogares, entre 2002 y 2012, en el promedio de los países latinoamericanos, los salarios urbanos medios subieron de 4,1 a 4,7 líneas de pobreza per cápita, mientras que entre 1990 y 2002 se habían elevado solo de 3,8 a 4,2 líneas de pobreza per cápita (CEPAL, 2013). Cabe señalar, sin embargo, que los salarios reales generalmente crecieron con tasas más bajas que los incrementos de la productividad laboral, lo que indica la relevancia adicional del funcionamiento de la institucionalidad del trabajo (CEPAL/ OIT, 2012).

La evolución diferenciada de la productividad laboral a nivel de las ramas de actividad, resultado de cambios intra e intersectoriales, también repercutió en las brechas de productividad entre estas ramas. Como se observa en el cuadro 2 a nivel regional, en el período 1990-2002 se ensancharon las brechas de productividad entre las ramas de actividad (tanto en el promedio ponderado de las productividades, como en el promedio simple de las productividades a nivel de las ramas), profundizándose la heterogeneidad estructural que caracteriza a la región. En contraste, en el período siguiente las brechas se reducen aproximadamente en la misma magnitud del CUADRO 2

América Latina y el Caribe (23 países): coeficiente de variación de la productividad laboral de las ramas de actividad (En promedios)

\begin{tabular}{lcc}
\hline & Promedio ponderado & Promedio simple \\
\hline 1990 & 0,78 & 0,96 \\
2002 & 1,05 & 1,04 \\
2002 & 1,63 & 1,15 \\
$2010-2011$ & 1,36 & 1,08 \\
\hline
\end{tabular}

Fuente: Jürgen Weller y Cornelia Kaldewei, "Empleo, crecimiento sostenible e igualdad", serie Macroeconomía del Desarrollo, $\mathrm{N}^{\circ} 145$ (LC/L.3743), Santiago de Chile, Comisión Económica para América Latina y el Caribe (CEPAL), 2013.

Nota: las primeras dos líneas (1990 y 2002) se basan en cálculos de la productividad sobre la base de dólares constantes de 1995; las líneas siguientes (2002 y 2010-2011) se basan en cálculos de la productividad a partir de dólares constantes de 2005. La columna "Promedio ponderado" se refiere al coeficiente de variación de la productividad de las ramas en el promedio ponderado de los países. 
ensanchamiento previo, lo que se relaciona con el cambio de las pautas de la generación de empleo en segmentos con diferentes niveles de productividad, aspecto que se aborda en la sección siguiente.

En resumen, en el decenio 2003-2012, procesos de cambio intra e intersectorial generaron moderados aumentos (con significativas diferencias entre los países) en la productividad laboral. Esto facilitó incrementos del salario real y mejoras en indicadores no salariales del empleo.

\section{c) El crecimiento económico y la generación de} empleo en los segmentos productivos

Como se planteó en la sección III, en mercados laborales heterogéneos, además de revisar el impacto de cambios en los indicadores agregados registrados entre y dentro de ramas de actividad, es indispensable tomar en cuenta cambios ocurridos entre y dentro de segmentos de diferentes niveles de productividad. En esta subsección se ilustra la relevancia de este segundo aspecto ${ }^{22}$.

Como se aprecia en el gráfico 5, mientras que en los años noventa la generación de empleo urbano según segmentos de productividad se concentró de manera

22 Dado que con la información disponible no es posible medir el tamaño de estos segmentos de manera frecuente, se utilizan indicadores laborales como proxy. De esta manera, desde hace mucho tiempo, la CEPAL mide el tamaño de los segmentos urbanos de baja productividad con la proporción de ocupados que se desempeñan como trabajadores por cuenta propia (excluidos los profesionales y técnicos), los asalariados y empleadores de microempresas, las personas que trabajan en servicio doméstico y los trabajadores familiares no remunerados. preponderante en aquellos de baja productividad, los que —en el promedio simple de los países con informaciónaumentaron su proporción en el empleo urbano del 45,7\% al $50,1 \%$. A partir de alrededor de 2002, en casi todos los países de la región se expandió la proporción del empleo en los segmentos de productividad alta y media, en tanto que la de los segmentos de baja productividad descendió, en el promedio, al 44,1\%.

Debido a las limitaciones de la disponibilidad de datos, en el análisis de la relación entre el crecimiento económico y las características de la generación de empleo se trabaja con dos categorías de ocupación como proxies para los segmentos laborales determinados por la demanda y la oferta, respectivamente: el empleo asalariado y el trabajo por cuenta propia ${ }^{23}$.

En el gráfico 6 se observa, para la región en su conjunto, una elevada correlación positiva $($ de 0,86$)$ entre el crecimiento económico y el empleo asalariado respecto del período 1995-2012, ya que el empleo asalariado aumenta notoriamente en años de alto crecimiento económico y se expande muy poco en años de estancamiento o crisis económica.

Al contrario, la relación es menos clara entre el crecimiento económico y el trabajo por cuenta propia. Así, en varios años el comportamiento del trabajo por cuenta propia fue contra-cíclico, lo que refleja la dinámica desde

\footnotetext{
23 Si bien no todo el empleo asalariado corresponde al segmento determinado por la demanda, y no todo el trabajo por cuenta propia al segmento determinado por la oferta, como se verá a continuación la gran mayoría del primero responde a la dinámica determinada por la demanda y la mayor parte del segundo a la dinámica determinada por la oferta.
}

América Latina: proporción de los ocupados en sectores de baja productividad, como porcentaje de los ocupados urbanos, 1990-2002 y 2002-2012

(En porcentajes)
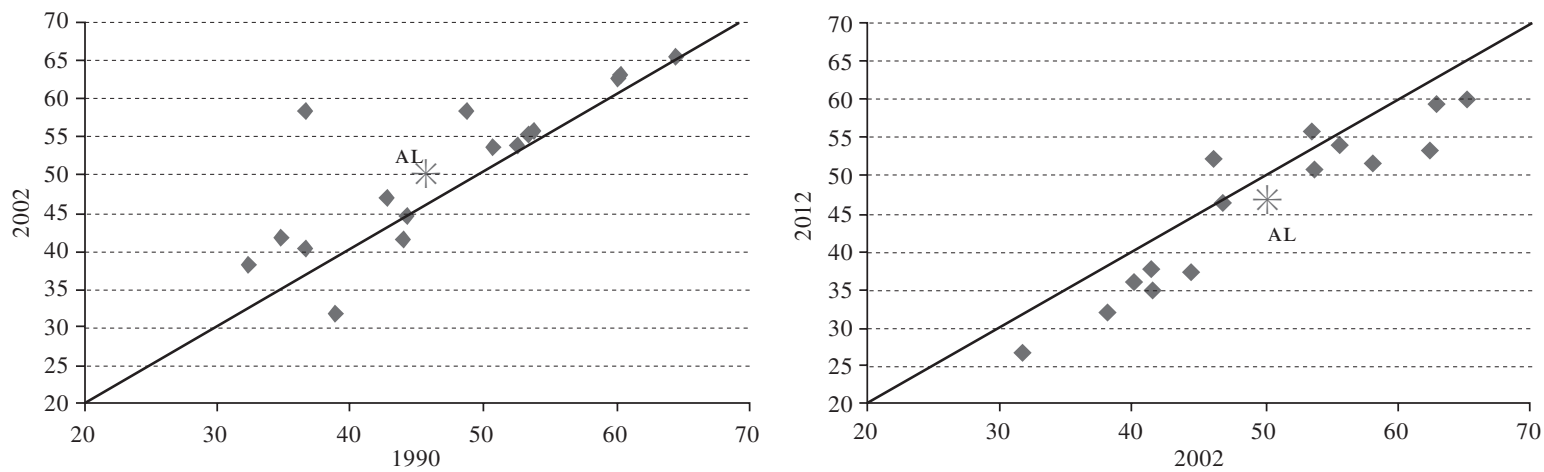

Fuente: elaboración propia sobre la base de Comisión Económica para América Latina y el Caribe (CEPAL), Panorama Social de América Latina, 2013 (LC/G.2580), Santiago de Chile, 2013. Publicación de las Naciones Unidas, Nº de venta: S.14.II.G.6.

AL: América Latina. 


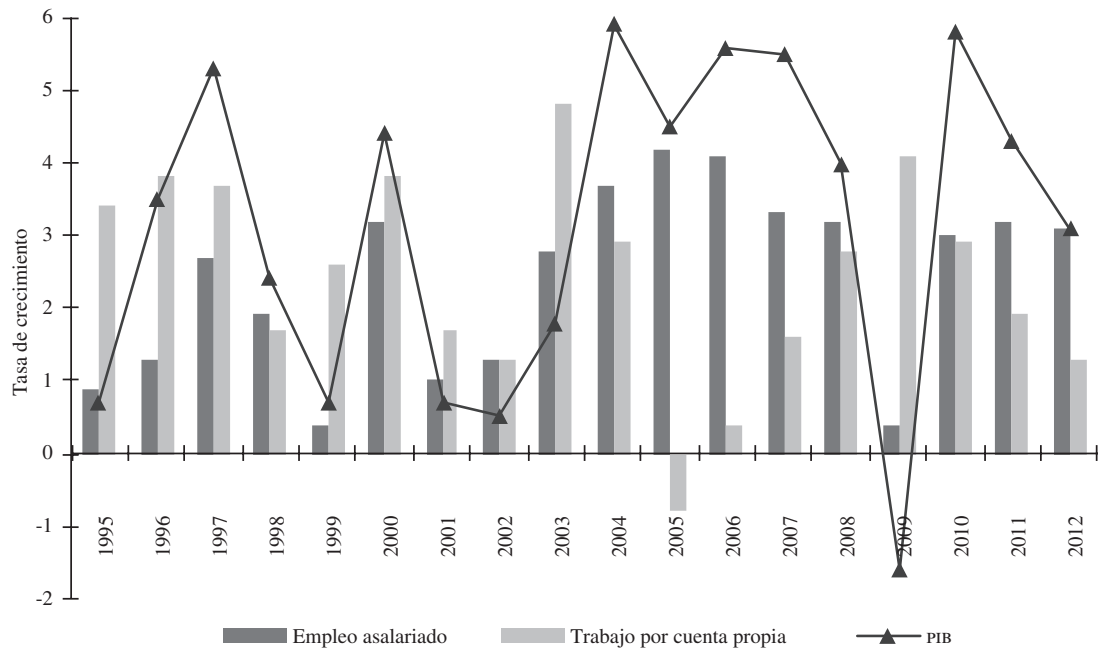

Fuente: elaboración propia sobre la base de información oficial de los países y de la Comisión Económica para América Latina y el Caribe (CEPAL).

PIB: producto interno bruto.

la oferta (por ejemplo, en 1995, 1996, 1999 y 2009 en el contexto de una débil generación de empleo asalariado, y entre 2005 y 2007 , en un contexto de una elevada y relativamente prolongada creación de puestos de trabajo asalariado). Este comportamiento refleja el carácter de los segmentos de baja productividad, dinamizados desde la oferta laboral según las necesidades de los hogares.

Sin embargo, también se observan años con un comportamiento procíclico en el trabajo por cuenta propia, tanto en el contexto de un crecimiento económico relativamente elevado $(1997,2000,2004,2008$ y 2010) - en el que no solo hubo una alta demanda laboral, sino que las personas necesitadas de ingresos laborales percibieron oportunidades favorables para emprender el trabajo independiente - como de un crecimiento bajo (2001 y 2002).

Estas variadas dinámicas subrayan la heterogeneidad interna de los segmentos de baja productividad, mencionada en la sección III. Por cuenta propia no solo trabajan personas excluidas del empleo asalariado, sino también existe un subsegmento dinámico que refleja la búsqueda de oportunidades. Como resultado agregado de las diferentes lógicas, en el período 1995-2012 a nivel regional la correlación entre el crecimiento del PIB y la generación de trabajo por cuenta propia fue de $-0,23$ (es decir, prevaleció el factor contracíclico).

Estos mismos resultados también se encuentran a nivel de los países. Tal como se indica en el cuadro 3 para
14 países, en la mediana el empleo asalariado tiene un coeficiente de correlación de 0,58 respecto del crecimiento económico, mientras que para el trabajo por cuenta propia este indicador es de $-0,27$. Con bastante diferencia entre los países, el empleo asalariado evoluciona de manera claramente procíclica. En contraste, la presencia de dinámicas tanto pro como contracíclicas del trabajo por cuenta propia genera coeficientes de correlación bastante bajos; el signo negativo que se observa en casi todos los países indicaría que prevalece la dinámica contracíclica.

De esta manera, el mayor crecimiento económico favoreció sobre todo a la generación de empleo asalariado, lo que contribuyó a la formalización laboral. Dado que la evolución del empleo asalariado se correlaciona estrechamente con el crecimiento económico, en el agregado este crecimiento es más determinante para la generación de empleo total en los países con mayor grado de asalarización ${ }^{24}$ (Weller, 2012).

Por otra parte, la elasticidad empleo asalariadoproducto en la mediana alcanza aproximadamente a 0,5 para el conjunto del período 1995-2012. Si bien se registra una gran variación entre los países, la pauta predominante indica que hay esfuerzos consistentes para incrementar la productividad, lo que (en el agregado) se ve parcialmente contrarrestado por la expansión —si

\footnotetext{
${ }^{24}$ Proporción del empleo asalariado en el empleo total.
} 
América Latina (países seleccionados): coeficientes de correlación empleocrecimiento económico y elasticidad empleo asalariado-PIB, 1995-2012

\begin{tabular}{|c|c|c|c|c|}
\hline & \multicolumn{3}{|c|}{ Coeficiente de correlación empleo-crecimiento económico } & \multirow{2}{*}{$\begin{array}{c}\text { Elasticidad empleo } \\
\text { asalariado-PIB }\end{array}$} \\
\hline & Empleo total & Empleo asalariado & $\begin{array}{c}\text { Trabajo por cuenta } \\
\text { propia }\end{array}$ & \\
\hline Argentina (17) & 0,71 & 0,77 & $-0,07$ & 0,56 \\
\hline Brasil (18) & 0,63 & 0,62 & 0,21 & 0,75 \\
\hline Chile (17) & 0,54 & 0,65 & $-0,27$ & 0,38 \\
\hline Colombia (18) & 0,15 & 0,53 & $-0,34$ & 0,26 \\
\hline Costa Rica (18) & 0,37 & 0,45 & $-0,27$ & 0,59 \\
\hline Ecuador (17) & $-0,19$ & $-0,13$ & $-0,01$ & 0,54 \\
\hline El Salvador (16) & 0,04 & 0,44 & $-0,30$ & 1,32 \\
\hline Honduras (14) & $-0,31$ & 0,20 & $-0,03$ & 0,45 \\
\hline México (17) & 0,79 & 0,87 & $-0,58$ & 0,91 \\
\hline Panamá (18) & 0,34 & 0,70 & $-0,42$ & 0,50 \\
\hline Perú (13) & 0,08 & 0,33 & $-0,08$ & 0,37 \\
\hline República Dominicana (18) & 0,61 & 0,20 & 0,50 & 0,26 \\
\hline Uruguay (11) & 0,67 & 0,77 & $-0,30$ & 0,06 \\
\hline Venezuela (República Bolivariana de) (18) & 0,47 & 0,78 & $-0,35$ & 1,05 \\
\hline América Latina (mediana) & 0,42 & 0,58 & $-0,27$ & 0,52 \\
\hline
\end{tabular}

Fuente: elaboración propia sobre la base de información oficial de los países y de la Comisión Económica para América Latina y el Caribe (CEPAL).

Nota: entre paréntesis se indica el número de años con información disponible para cada país. PIB: producto interno bruto.

bien menos intensa en el período reciente- de empleos de baja productividad, como reflejo de la persistente heterogeneidad estructural.

Estos cambios en las pautas de generación de empleo contribuyeron a mejorar los ingresos laborales medios. Específicamente, la concentración de la generación de los nuevos empleos en segmentos de productividad alta o media conllevó un aumento de los ingresos laborales medios, como se indica - sobre la base de un cálculo de descomposición- en el gráfico 7.

Mientras que en los años noventa la expansión del empleo sobre todo en los segmentos de baja productividad incidió de manera levemente negativa en el ingreso laboral medio, en el período siguiente una parte del aumento de este ingreso se debe a la reubicación de una porción de la fuerza de trabajo desde segmentos de baja productividad hacia segmentos de productividad media o alta.

En vista de que el grado de la formalidad laboral es mucho más elevado en las categorías de ocupación que conforman los segmentos de productividad media y alta, la recomposición revisada favorece a las mejoras en los niveles de formalidad y, en consecuencia, en la calidad del empleo ${ }^{25}$.

${ }^{25}$ Véanse Weller y Roethlisberger (2011) y ort (varios años). Además, influyen las políticas de formalización que pueden abarcar ambos segmentos (véase al respecto la sección IV.2.b).
La concentración de la mayor parte de los nuevos puestos de trabajo en los segmentos de productividad alta y media, como reflejo de la dinámica demanda laboral, se relaciona con la expansión del empleo formal en el sector terciario, que en circunstancias menos favorables es típicamente refugio de empleo informal y de baja productividad, que surge a causa de la presión de la oferta laboral (CEPAL, 2014b).

Como se señala en el gráfico 8 , en muchos países el comercio y los servicios, y también la construcción, registraron tasas de crecimiento del empleo formal marcadamente superiores a las tasas en la industria manufacturera y la agricultura. Esta desagregación sectorial del empleo formal refleja, sobre todo, la dinámica del crecimiento económico focalizada crecientemente en las actividades relacionadas con la demanda interna (rubros productores principalmente de bienes y servicios no transables), con lo que la demanda laboral se concentró en las actividades correspondientes facilitando la expansión del empleo formal en estos rubros.

Las mayores brechas entre la expansión del empleo total y del empleo formal se registran en el sector agropecuario, la minería, el comercio y los servicios comunales, sociales y personales. Esto obedecería a tres factores: primero, algunos de estos sectores se caracterizan por tener barreras de entrada poco exigentes, de manera que en períodos de bajo crecimiento en ellos se concentra el empleo surgido a partir de la dinámica 
GRÁFICO 7

América Latina (mediana de 16 países): descomposición de los incrementos del ingreso laboral, según los aportes intra e intersectorial de segmentos de diferentes niveles de productividad, 1990-2002 y 2002-2011

(En equivalentes de una línea de pobreza per cápita)

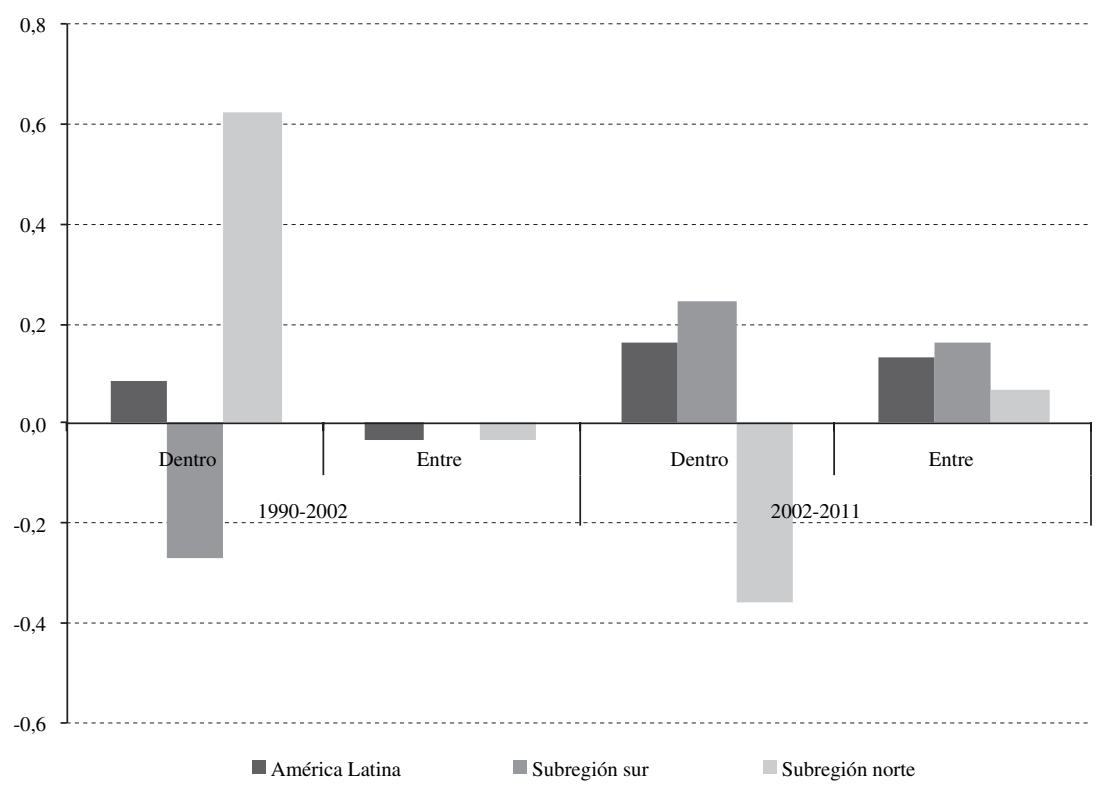

Fuente: elaboración propia sobre la base de Comisión Económica para América Latina y el Caribe (CEPAL), Panorama Social de América Latina, 2012 (LC/G.2557-P), Santiago de Chile, 2013. Publicación de las Naciones Unidas, N de venta: S.13.II.G.6.

GRÁFICO 8

América Latina (mediana de 11 países): empleo formal y total y valor agregado por rama de actividad, tasa de crecimiento anual, 2002-2012 (En porcentajes)

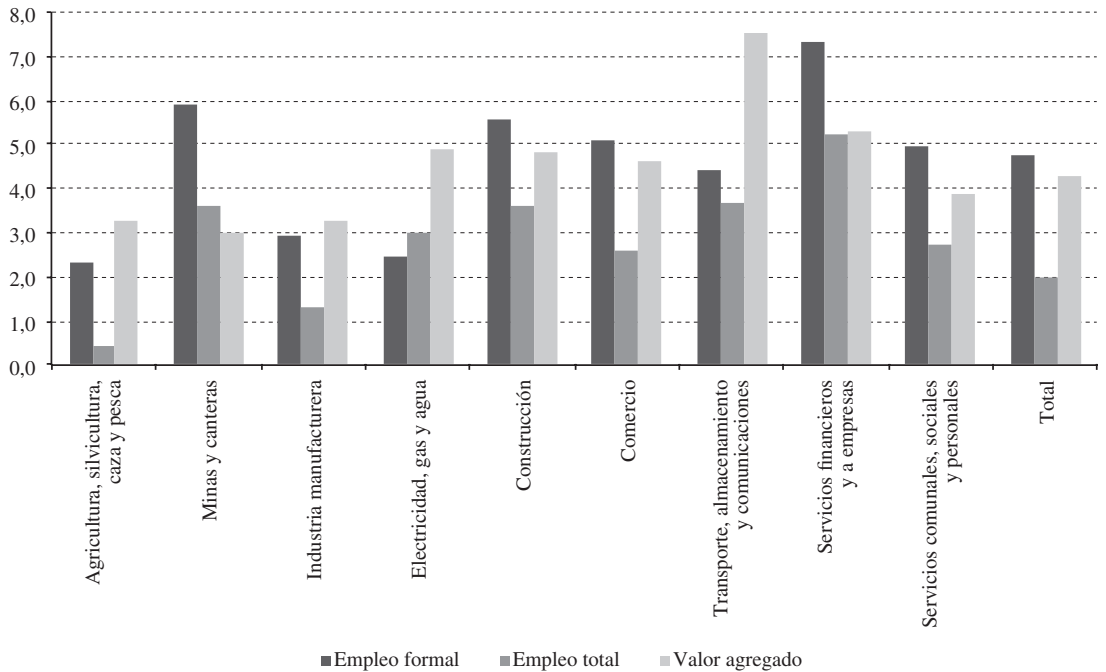

Fuente: elaboración propia sobre la base de datos oficiales de los países.

Nota: la información abarca los siguientes países: Argentina, Brasil, Chile, Costa Rica, Ecuador, El Salvador, Guatemala, México, Nicaragua, Panamá y Perú. Los datos del empleo formal reflejan la evolución de la cotización o afiliación a algún sistema de protección social contributivo, con la excepción del Brasil (registro de empleo formal), el Ecuador y el Perú (encuestas de empresas de ramas de actividad seleccionadas con 10 trabajadores o más). Los datos sobre el crecimiento anual del empleo total y del valor agregado se refieren al período 2002-2012, salvo en los casos del Brasil, Guatemala, el Perú (2002-2011), el Ecuador (2003-2012) y Nicaragua (2003-2010). 
de la oferta laboral, y esta dinámica se atenúa en un contexto de mayor crecimiento económico. Segundo, en algunos sectores, sobre todo el del comercio, se observó una gran expansión de actividades formales, en parte en detrimento de segmentos informales. Tercero, los esfuerzos de la formalización laboral pueden haber tenido un efecto diferenciado entre los sectores, con mayores avances en dichos rubros.

En resumen, las características de la demanda laboral han incidido en una recomposición del empleo que ha dado lugar a avances en su calidad salarial y no salarial, así como a mejoras dentro de las ramas de actividad.

\section{d) El crecimiento, las características de la demanda laboral y la reducción de la desigualdad salarial}

El crecimiento económico y sus características jugaron un papel en el tercero de los hechos estilizados, la reducción de la brecha salarial. Tal como se ha constatado en la sección IV, el aumento de la cantidad de empleo no contribuyó directamente a reducir la desigualdad a nivel de los hogares, pero sus características pueden haber redundado en una menor brecha en los ingresos laborales, que fue el mecanismo más importante al respecto. Un factor relevante detectado sobre el particular es el incremento del nivel educativo, que habría favorecido las mejoras en la distribución al reducirse las brechas entre los quintiles de hogares con diferentes niveles de ingreso per cápita (Cruces, García Domenech y Gasparini, 2012). Otro factor importante son las políticas laborales aplicadas en este período (véase la sección IV.2).

Hay indicios de que también el sesgo de la demanda laboral en favor de los más calificados se ha revertido durante la década de 2000.

En los cuatro estudios de caso presentados en López-Calva y Lustig (2010) sobre la Argentina, el
Brasil, México y el Perú se identifica, entre las causas de menores brechas de ingresos, un menor sesgo de la demanda en favor de personal más calificado como resultado del término del impacto del cambio tecnológico intensivo en calificaciones, que fue incentivado por las reformas económicas de los años ochenta y noventa.

Gasparini y otros (2011) argumentan que la demanda de mano de obra menos calificada habría aumentado en el contexto de la expansión de los bienes básicos y procesos intrasectoriales, como la difusión tecnológica y el desequilibrio (mismatch) entre las calificaciones de personas con mayores niveles de educación formal y los requerimientos de los puestos disponibles. El Banco Mundial (2012) plantea la hipótesis de que la concentración del crecimiento en los sectores productores de bienes y servicios no transables habría reducido la demanda de personal de mayor nivel de calificación, que en estos sectores sería más débil que en la industria manufacturera.

En el cuadro 4 se muestra para 15 países la composición del empleo adicional, según nivel educativo y diferenciando el empleo asalariado (que reflejaría la demanda laboral de las empresas) del no asalariado (que representa diferentes dinámicas, predominando generalmente la presión desde la oferta) ${ }^{26}$. Se observa que, tal como se constató con respecto a los años noventa (Weller, 2000), la mayoría de los nuevos empleos se genera como empleo asalariado para personas de nivel educativo medio y alto. Por otra parte, como reflejo de los avances de los sistemas educativos, solo un porcentaje

\footnotetext{
${ }^{26}$ Por otra parte, se presenta el resultado para un conjunto de siete países respecto de los cuales se dispone de la misma información que acerca de los años noventa (Weller, 2000). Cabe señalar que los datos allí presentados abarcan un período previo a la "media década perdida", que se inició hacia fines de los años noventa.
} CUADRO 4

América Latina (mediana de 7 y 15 países): composición del empleo neto adicional, según nivel educativo, para asalariados y no asalariados, alrededor de 2002-2012

\begin{tabular}{|c|c|c|c|c|c|}
\hline \multirow{2}{*}{ Grupo de países } & \multirow{2}{*}{ Categoría de ocupación } & \multicolumn{4}{|c|}{ Nivel educativo } \\
\hline & & Hasta 9 años & 10 a 12 años & 13 años y más & Total \\
\hline \multirow{3}{*}{ Siete países } & Ocupados & 3,4 & 46,7 & 44,2 & 100,0 \\
\hline & Asalariados & 3,3 & 24,7 & 32,6 & 82,4 \\
\hline & No asalariados & $-5,6$ & 13,8 & 7,4 & 17,6 \\
\hline \multirow{3}{*}{15 países } & Ocupados & 4,7 & 46,3 & 44,2 & 100,0 \\
\hline & Asalariados & 3,3 & 26,4 & 32,6 & 77,9 \\
\hline & No asalariados & 4,1 & 13,8 & 8,6 & 22,1 \\
\hline
\end{tabular}

Fuente: elaboración propia sobre la base de las encuestas de hogares de los países.

Nota: los siete países presentados por separado son la Argentina, Bolivia (Estado Plurinacional de), el Brasil, Chile, Colombia, Costa Rica y el Perú. En los 15 países se incluye, además, al Ecuador, El Salvador, Honduras, México, Panamá, el Paraguay, la República Dominicana y Venezuela (República Bolivariana de). 
muy menor del nuevo empleo (alrededor de un 5\% en la mediana de los 15 países) corresponde a personas de hasta 9 años de educación.

Si se comparan los resultados respecto de los siete países para los que se hizo este mismo cálculo en relación con cierto período de los años noventa (Weller, 2000, pág. 157), se registra una demanda laboral levemente superior para las personas de bajo nivel educativo, cuyo número decae en el empleo no asalariado en la mediana de estos siete países, pero sube en el asalariado. Esto reflejaría una demanda laboral más equilibrada según nivel educativo, reduciéndose el sesgo de la demanda en favor de los más calificados. Sin embargo, en la mediana de 15 países tanto el empleo asalariado como el no asalariado se expanden para personas con un bajo nivel de escolarización y lo hacen un poco más para los no asalariados. De todas maneras, en comparación con el resultado de los años noventa, cuando la relación de generación de empleo para los menos calificados en el empleo asalariado con respecto al no asalariado representó alrededor de 0,5 (para siete países), en la década de 2000 aparentemente hubo una demanda laboral relativa levemente más intensa para este grupo de personas (con una relación entre el empleo asalariado y el no asalariado de 0,8 ), como también para el grupo más grande de países.

En resumen, la demanda laboral sigue favoreciendo la incorporación de personas de nivel educativo intermedio y alto, aunque además hubo nuevas oportunidades para personas con poca educación formal.

Para analizar las características sectoriales de la demanda laboral se procedió a una descomposición siguiendo la metodología de Berman, Bound y Griliches (1994), con la que se estiman los aportes de los cambios intra e intersectoriales tanto para la mayor demanda de personas de niveles altos e intermedios de educación formal, como para la menor demanda de personas de más bajo nivel de educación formal ${ }^{27}$.

\footnotetext{
${ }^{27}$ Se trata del resultado de la siguiente descomposición:

$$
\Delta S=\sum_{i=1}^{n} \Delta A_{i} S_{i}+\sum_{i=1}^{n} \Delta S_{i} A_{i}
$$

para $i=1, \ldots, n$ ramas de actividad, donde:

$\mathrm{S}=$ proporción de personal con un nivel educativo específico en el empleo asalariado total.

$\mathrm{S}_{i}=$ proporción de personal con un nivel educativo específico en la rama de actividad $\mathrm{i}$.

$\mathrm{A}_{i}=$ empleo asalariado en la rama i como proporción del empleo asalariado total.

Las barras indican los promedios de los valores correspondientes a los años iniciales y finales. De esta manera, el primer término del lado derecho de la ecuación capta la contribución de los cambios entre las ramas (es decir, las diferencias con respecto al crecimiento del empleo asalariado), mientras que el segundo término capta la
}

Como se advierte en el cuadro 5, igual que en los años noventa, la expansión del empleo asalariado para personas altamente calificadas se centró en el sector terciario. Los servicios - sumando los servicios comunales, sociales y personales y los servicios financieros, inmobiliarios y a empresas - fueron responsables de más de la mitad de estos nuevos empleos. En contraste con los años noventa, también los cambios en el comercio (por ejemplo, la expansión del comercio al por menor a gran escala: super e hipermercados, centros comerciales, y otros) incidieron en una mayor demanda de personal altamente calificado, y no solo debido a la expansión de este rubro (efecto de cambios intersectoriales), sino también a cambios intrasectoriales. Por el contrario, el aporte de la industria manufacturera a la demanda de personal de alto nivel de calificación fue débil, sobre todo a causa de la reducción de la participación del sector en el empleo total. Los cambios intrasectoriales influyeron en un aumento de la demanda de este tipo de trabajadores por parte de la industria manufacturera, si bien - tal como se indica en la última columna del cuadro 5a) — el incremento de la participación de personal de alto nivel educativo fue menor que en otros sectores. En términos relativos, destaca el aumento de categoría (upgrading) de las calificaciones demandadas en la construcción, la minería y, nuevamente, el comercio.

El aumento de la proporción de los altamente calificados entre los asalariados se debió, en el saldo, casi exclusivamente a los cambios internos de las ramas de actividad ${ }^{28}$. En varios rubros, sobre todo del sector terciario pero también en la construcción, se generaron nuevos puestos de este tipo a partir de cambios intersectoriales, sin embargo, estos empleos adicionales se compensaron en gran medida por las pérdidas en otras ramas de actividad.

También el incremento de la participación de asalariados con un nivel intermedio de educación formal se debe principalmente a los cambios intrasectoriales (y, por lo tanto, en parte al elevamiento general del nivel educativo). No obstante, en comparación con los asalariados de más alto nivel de educación, los cambios intersectoriales tuvieron una repercusión claramente más notoria. Llama la atención al respecto el marcado impacto de la demanda laboral del comercio y, en magnitudes

contribución de los cambios dentro de la rama (esto es, las variaciones de la participación del personal con un nivel educativo específico en el empleo asalariado de la rama).

${ }^{28}$ Esto no necesariamente implica transformaciones productivas; en muchos casos este cambio dentro de la rama consiste en la sustitución de personal de mayor edad, que se jubila, por personas jóvenes con más alto nivel de educación formal. 
CUADRO 5

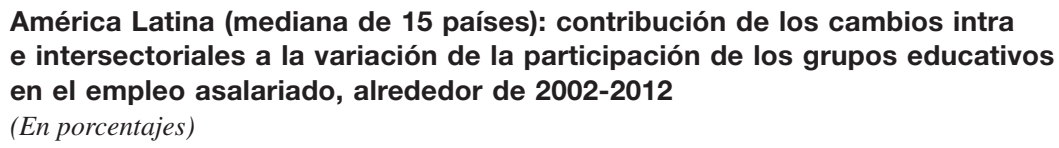

a) Asalariados de alto nivel educativo (13 años y más)

\begin{tabular}{|c|c|c|c|c|}
\hline & Cambios intrasectoriales & Cambios intersectoriales & Total & Incremento relativo $^{\mathrm{a}}$ \\
\hline Total & 4,09 & 0,20 & 4,29 & 1,00 \\
\hline Sector agropecuario & 0,14 & $-0,48$ & $-0,34$ & 1,01 \\
\hline Minería & 0,07 & 0,11 & 0,18 & 1,19 \\
\hline Industria manufacturera & 0,42 & $-0,29$ & 0,13 & 0,72 \\
\hline Construcción & 0,08 & 0,22 & 0,31 & 1,42 \\
\hline Comercio & 0,75 & 0,27 & 1,02 & 1,18 \\
\hline Transporte y comunicaciones & 0,26 & 0,16 & 0,42 & 1,14 \\
\hline Servicios & 2,37 & 0,22 & 2,59 & 0,94 \\
\hline
\end{tabular}

b) Asalariados de nivel educativo intermedio (10 a 12 años)

\begin{tabular}{|c|c|c|c|}
\hline & Cambios intrasectoriales & Cambios intersectoriales & Total \\
\hline Total & 3,56 & 0,84 & 4,38 \\
\hline Sector agropecuario & 0,41 & $-0,03$ & 0,37 \\
\hline Minería & $-0,02$ & 0,09 & 0,07 \\
\hline Industria manufacturera & 1,18 & $-0,69$ & 0,49 \\
\hline Construcción & 0,54 & 0,33 & 0,88 \\
\hline Comercio & 0,80 & 0,89 & 1,69 \\
\hline Transporte y comunicaciones & 0,43 & 0,19 & 0,62 \\
\hline Servicios & 0,20 & 0,06 & 0,25 \\
\hline
\end{tabular}

c) Asalariados de bajo nivel educativo (hasta 9 años)

\begin{tabular}{|c|c|c|c|}
\hline & Cambios intrasectoriales & Cambios intersectoriales & Total \\
\hline Total & $-7,56$ & $-1,01$ & $-8,58$ \\
\hline Sector agropecuario & $-0,61$ & $-1,74$ & $-2,34$ \\
\hline Minería & $-0,06$ & 0,08 & 0,02 \\
\hline Industria manufacturera & $-1,57$ & $-1,24$ & $-2,81$ \\
\hline Construcción & $-0,66$ & 0,77 & 0,11 \\
\hline Comercio & $-1,50$ & 0,84 & $-0,66$ \\
\hline Transporte y comunicaciones & $-0,67$ & 0,24 & $-0,43$ \\
\hline Servicios & $-2,49$ & 0,03 & $-2,46$ \\
\hline
\end{tabular}

Fuente: elaboración propia sobre la base de las encuestas de hogares de los países.

a Proporción entre el crecimiento porcentual del grupo educativo en la rama de actividad y el crecimiento porcentual del grupo educativo en el conjunto de los asalariados.

Nota: los países cubiertos son: Argentina, Brasil, Bolivia (Estado Plurinacional de), Chile, Colombia, Costa Rica, Ecuador, El Salvador, Honduras, México, Panamá, Paraguay, Perú, República Dominicana y Venezuela (República Bolivariana de).

mucho más acotadas, de la construcción, el transporte y las comunicaciones. El comercio también destaca entre las ramas con un importante acrecentamiento del personal de nivel educativo intermedio a causa de los cambios intrasectoriales, lo que subraya el peso de la modernización sectorial ya mencionado a propósito del personal de nivel educativo más elevado. También la industria manufacturera muestra claros indicios de upgrading de la estructura de personal, con pronunciados incrementos del personal de educación intermedia y (como ya se vio) alta.

La contracción del empleo de personal de bajo nivel de educación formal también se centró en los cambios internos de las ramas de actividad. El upgrading de la estructura educativa en los servicios, la industria manufacturera y el comercio incidió en este proceso. Sin embargo, también contribuyeron las transformaciones intersectoriales, sobre todo la reducción de la proporción del empleo en la agricultura y la industria manufacturera. Por otra parte, surgieron empleos para personas de bajo nivel de educación formal como consecuencia de la expansión, especialmente, del comercio y la construcción.

Por lo tanto, la concentración del crecimiento económico en el sector terciario durante el período 2003-2012 no implicó una baja de la demanda de personas de altos niveles de calificación. Esta, al igual 
que en los años noventa (Weller, 2000), se centró en el sector terciario. Específicamente en el comercio se observan indicios de una modernización que fomenta esta demanda ${ }^{29}$. Por otra parte, y a diferencia de los años anteriores, en algunos casos las transformaciones intra y, en ciertos casos, intersectoriales estimularon la demanda de personal de calificación intermedia y, en menor grado, de educación formal baja. Nuevamente, estos procesos se concentraron en el sector terciario, si bien las transformaciones internas también favorecieron la expansión del empleo para el grupo educativo intermedio en la industria manufacturera y el sector agropecuario ${ }^{30}$. Este cambio parcial en las pautas de la demanda laboral habría favorecido a los ingresos de los trabajadores relativamente menos calificados y contribuido a reducir las brechas salariales.

Además, la recomposición del empleo hacia los segmentos de media y alta productividad incidió favorablemente en los ingresos medios de los segmentos de baja productividad. Como se mencionó previamente, el empleo en estos segmentos es heterogéneo. En países con un menor PIB per cápita y, por lo tanto, con menor grado de asalarización de los ocupados, una mayor parte del empleo por cuenta propia representa la presión desde la oferta (Weller y Kaldewei, 2013, págs. 35-39). En estos países, tal como se desprende de los planteamientos teóricos mencionados en la sección IV, los ingresos laborales medios relativos del trabajo por cuenta propia son más bajos que en aquellos países con menor proporción de los ocupados por cuenta propia (donde una mayor parte de ellos trabajan de esta manera en búsqueda de las ventajas relacionadas con este tipo de trabajo) (Weller, 2012, pág. 35).

Por consiguiente, una reducción relativa del empleo en segmentos de baja productividad también favorecería los cambios intrasectoriales al aminorar la presión desde la oferta y, específicamente, aumentaría los ingresos medios en dichos segmentos. En efecto, entre 1990 y 2000-2002, los ingresos medios de los asalariados (excluidos los profesionales y técnicos) en empresas con cinco y más trabajadores se mantuvieron

\footnotetext{
${ }^{29}$ Este resultado contradice lo planteado por el Banco Mundial (2012), según el cual el fortalecimiento de los sectores no transables se habría traducido en una caída de la demanda de mano de obra calificada.

30 Según Klasen, Otter y Villalobos Barría (2012), el auge de los recursos naturales a mediados de la década del 2000 tuvo un efecto distributivo favorable en las zonas rurales de Honduras, al mejorar los ingresos de los trabajadores agropecuarios. Por otra parte, hay evidencia anecdótica de varios países en cuanto a que la reducción de la oferta laboral ha derivado en mejoras de los ingresos en el sector agropecuario.
}

constantes en términos de líneas de pobreza, mientras que los de los trabajadores por cuenta propia (excluidos los profesionales y técnicos) cayeron en 0,6 líneas de pobreza. En contraste, entre 2000-2002 y 2009-2010 los ingresos de ambos grupos aumentaron (en el promedio) en 0,4 y 0,6 líneas de pobreza, respectivamente ${ }^{31}$.

En resumen, el mejor contexto económico favoreció a los ingresos de los ocupados en la base de la escala de ingresos laborales, principalmente debido a dos mecanismos vinculados: la mayor demanda laboral (sobre todo de actividades del sector terciario) de trabajadores de niveles medios y bajos de educación y la reducción de la presión desde la oferta sobre los segmentos de baja productividad.

\section{La institucionalidad laboral y las características del empleo}

Como ya se planteó, además del contexto económico y productivo, es la institucionalidad laboral la que incide mayormente en la evolución del empleo y sus características. Recientemente, los cambios en la institucionalidad laboral contribuyeron a las mejoras, sobre todo, de la calidad del empleo y a la reducción de la desigualdad salarial.

Durante los años dos mil en muchos países se modificó la perspectiva sobre la institucionalidad laboral. Cabe recordar que las reformas de los años noventa pusieron énfasis en ampliar la gama de contratos disponibles, añadiendo al contrato "típico" de duración indeterminada contratos de duración determinada, ampliando el uso del período de prueba y facilitando modalidades de subcontratación. La segunda tendencia consistió en el abaratamiento del despido, destacándose como medidas la ampliación de la definición del despido por causa justa y la introducción de sistemas de protección al desempleo por medio de cuentas individuales (Vega Ruiz, 2005).

Generalmente y como parte de paquetes de estabilización macroeconómica, en los años ochenta en muchos países los salarios mínimos reales cayeron pronunciadamente, mientras en los años noventa prevaleció su estancamiento. Además, en muchos casos se dio un acentuado debilitamiento de la inspección del trabajo, en un marco más amplio de estrategias para reducir el papel y el tamaño del Estado. En consecuencia, en numerosos casos la brecha entre las disposiciones legales y la realidad laboral tendió a ampliarse (Bensusán, 2006).

${ }^{31}$ Cálculo propio sobre la base de CEPAL (2012). 
Por otra parte, aminoró la proporción del empleo en los segmentos de productividad media y alta (debido a bajas tasas de crecimiento económico, una marcada caída relativa del empleo público y, por lo menos transitoriamente, una reducción de la elasticidad empleo asalariado-producto), lo que redundó en una "flexibilización de hecho". Eso contribuyó, además, a la pérdida de fuerza de los movimientos sindicales.

Los mediocres resultados de las reformas aplicadas durantes los años ochenta y noventa y las diferentes crisis que se produjeron en América Latina y el Caribe a partir de mediados de los años noventa debilitaron las políticas laborales orientadas a la desregulación como instrumento clave para fomentar la generación de empleo. En este escenario, durante los años dos mil emergieron en la región nuevas propuestas políticas bajo la premisa de que frente al contexto de la globalización no existe una respuesta única en términos de reestructuración productiva y políticas económicas, así como con respecto a las políticas laborales (Fraile, 2009; Weller, 2009; Lee y McCann, 2011). Al mismo tiempo, en el debate internacional empezó a prevalecer una mayor cautela ante propuestas de desregulación radical (BID, 2003; Freeman, 2005). En la región contribuyó a este cuestionamiento el hecho de que el efecto de una reforma laboral liberalizadora de gran alcance en el crecimiento económico fue estimado como más bien limitado (BID, 1997), y que las expectativas de generación de empleo formal que se pusieron en las reformas no se cumplieron.

En la década de 2000, en algunos países mejoraron las condiciones de la organización sindical y se logró frenar o invertir la tendencia predominante de un descenso de la sindicalización ${ }^{32}$. En este escenario se registró una ligera ampliación del espectro temático de la negociación colectiva, al extenderse a nuevos grupos de trabajadores, como los temporeros y las empleadas domésticas. En algunos casos, se limitó la subcontratación de personal debido a los abusos detectados en la aplicación de este instrumento contractual y se asemejaron las condiciones de trabajo en el empleo doméstico a las de otros trabajadores.

Ante la disparidad entre la legislación vigente y los grados de cumplimiento, en diversos países aumentaron los recursos disponibles para la inspección del trabajo a objeto de mejorar el cumplimiento de las normas existentes. Además, en muchos países se desarrollaron esquemas destinados a incentivar la formalización empresarial y laboral, específicamente en la pequeña y microempresa (pymes) (oIT, 2014). En vista de que

32 Véase OIT (2009) para una ilustración de la tendencia de una decreciente sindicalización entre 1989 y 2005. la informalidad se determina tanto por aspectos de la estructura productiva como por aspectos institucionales, las políticas de formalización hacen una contribución adicional a la moderación de la segmentación del mercado laboral. Específicamente, la formalización de la relación laboral es de gran relevancia para la calidad del empleo, pues la evidencia indica que un contrato formal de trabajo podría ser una "llave de acceso" a otros beneficios que caracterizan a los empleos de buena calidad (Weller y Roethlisberger, 2011; CEPAL/OIT/FAO, 2012).

Además, en varios países las reformas de las relaciones laborales individuales tuvieron un sello protector. Por ejemplo, en algunos de ellos se redujo el número de horas semanales de trabajo, se aumentó el pago de las indemnizaciones en caso de despido injustificado, se restringió el uso de horas extras o se incrementó el pago correspondiente, y se ampliaron los períodos pre y postnatal.

$\mathrm{Al}$ mismo tiempo, en algunos países se fortaleció el seguro de desempleo o se crearon modelos nuevos (varios países están en proceso de hacerlo) para ampliar los sistemas de protección de los trabajadores en un contexto de mercados estructuralmente más volátiles. Además, en muchas naciones se emprendieron políticas de salario mínimo más activas ${ }^{33}$. Tal como en los años noventa, en el caso de México la caída del salario mínimo se identificó como un factor que contribuyó significativamente a la ampliación de las brechas de ingresos (Cortez, 2001; Bosch y Manacorda, 2010), en relación con el período reciente, Cornia (2014), Keifman y Maurizio (2012), y CEPAL (2014c) encontraron que en varios países los aumentos del salario mínimo y la mayor formalidad - $\mathrm{O}$ la interacción de ambos - han sido factores importantes para la reducción de dichas brechas.

En resumen, al contrario de lo ocurrido durante las décadas precedentes, con respecto al citado doble objetivo de la institucionalidad laboral en el período reciente se implementaron mayores medidas que fortalecen los derechos individuales y colectivos de los trabajadores; aunque, por lo general, sin dejar de lado el objetivo de un funcionamiento eficiente del mercado laboral, que fue apoyado por medidas como las políticas de formalización empresarial y laboral.

\footnotetext{
33 En la mediana de 20 países, entre 1990 y 2003 el salario mínimo real no registró cambios, mientras que en el período comprendido entre 2003 y 2012 se observa un incremento anual de $2,0 \%$. Si los aumentos se ponderan por la población en edad de trabajar, el incremento anual del período reciente fue de $4,4 \%$ (cálculo propio sobre la base de información oficial de los países).
} 


\section{V}

\section{Conclusiones}

En el decenio 2003-2012, los mercados laborales de América Latina y el Caribe mostraron un desempeño que, en varios aspectos, representó una ruptura con la evolución previa. En particular, la tasa de desempleo abierto descendió ostensiblemente a raíz de un aumento de los niveles de ocupación, los indicadores de calidad del empleo mejoraron en el contexto de una mayor formalidad laboral, y se redujeron las brechas de ingresos entre los trabajadores más y menos calificados.

Para comprender los factores que habrían influido en tal desempeño, en este artículo se plantea que habría que analizar el comportamiento del entorno económicoproductivo (el crecimiento económico, la evolución de la productividad laboral y los cambios en la heterogeneidad estructural) y de la institucionalidad laboral. La revisión de estos factores en dicho decenio muestra que su combinación fue la que marcó los tres hechos estilizados que caracterizaron a la evolución laboral reciente. Un crecimiento económico relativamente elevado estimuló la demanda laboral, lo que favoreció una dinámica generación de empleo sobre todo en segmentos de productividad media y alta, facilitando una mayor formalidad e incrementos de los ingresos laborales. Las características de la demanda laboral, centrada en las actividades productoras de bienes y servicios no transables (sector terciario y construcción), marcaron las pautas de la generación de empleo. Transformaciones inter e intrasectoriales conllevaron aumentos de la productividad, relacionados —en varias ramas de actividad, como comercio y transporte, almacenaje y comunicaciones - con procesos de upgrading de la estructura ocupacional, que facilitaron mejoras en la calidad del empleo. Por otra parte, las características de la demanda laboral mejoraron las opciones de inserción de trabajadores de nivel educativo bajo y medio, lo que incidió en una merma de las brechas de ingreso. Los cambios institucionales también contribuyeron a disminuir estas brechas, y dieron lugar a una mayor formalización del empleo y mejoras en los indicadores de su calidad. Mientras que la fuerte generación de empleo fue un factor clave para el descenso de la pobreza, la reducción de las brechas de ingreso lo fue para avanzar en el retroceso de la desigualdad a nivel de los hogares.

A pesar de los avances revisados que revirtieron las tendencias previas, los mercados laborales de la región continúan mostrando agudas debilidades, tales como altos niveles de informalidad, grandes brechas de productividad, un elevado porcentaje de trabajadores pobres y desprotegidos, bajos niveles de participación en el mercado laboral de las mujeres, notorias desigualdades laborales entre hombres y mujeres tanto dentro como fuera de los mercados del trabajo, discriminación de diferentes grupos de trabajadores, bajos índices de calidad del empleo, como también escasos niveles de capacitación continua, sindicalización y negociación colectiva. Obviamente, no obstante los avances recientes, los desafíos siguen siendo considerables.

En el futuro próximo hay varios aspectos que amenazan con frenar, por lo menos, el ritmo de las mejoras laborales. Primero, con un entorno global de menor dinamismo que en el pasado reciente, las perspectivas de crecimiento económico regional son menos promisorias debido a una demanda externa más acotada (CEPAL, 2014b). Al mismo tiempo, en muchos países la dinámica de la demanda interna, basada sobre todo en el consumo de los hogares, tiende a desacelerarse debido a factores como el fin del mejoramiento de los términos de intercambio (lo que atenúa el incremento del ingreso nacional disponible), el fin de las tendencias de apreciación cambiaria y los altos niveles de endeudamiento de los hogares. A nivel regional, ya en 2013 la generación de empleo fue débil, tanto en términos absolutos como en relación con la tasa de crecimiento económico alcanzado en ese año (CEPAL, 2014a).

Por parte de las políticas, en muchos países el enfoque de centrar la formalización en incentivos y en una supervisión más estricta podría arrojar rendimientos decrecientes, dado que ya se habría formalizado a muchas empresas y trabajadores con el potencial productivo capaz de asumir los costos correspondientes, mientras que otras empresas y trabajadores que permanecen en la informalidad reflejan la presión desde la oferta laboral y se caracterizan por tan bajos niveles de productividad que impiden, por lo menos, una formalidad plena. Esto requeriría repensar los instrumentos destinados a fomentar el desarrollo sobre todo de la micro y pequeña empresa (pymes). También es importante fortalecer el círculo virtuoso entre los incrementos de la productividad laboral y la calidad del empleo, para lo cual son elementos clave las mejoras en la educación, la formación profesional y la capacitación, así como el fortalecimiento de la "voz" de los trabajadores mediante la extensión de la organización sindical y la negociación colectiva. 


\section{Bibliografía}

Akerlof, George A. y Janet Louise Yellen (1986), Efficiency Wage Models of the Labor Market, Nueva York, Cambridge University Press.

Azevedo, João Pedro y otros (2013), "Is labor income responsible for poverty reduction? A decomposition approach", Policy Research Working Papers, $\mathrm{N}^{\circ}$ 6414, Washington, D.C., Banco Mundial.

Azevedo, João Pedro, Gabriela Inchauste y Viviane Sanfelice (2013), "Decomposing the recent inequality decline in Latin America", Policy Research Working Papers, $\mathrm{N}^{\circ}$ 6715, Washington, D.C., Banco Mundial.

Ball, Laurence M., Nicolás de Roux y Marc Hofstetter (2011), "Unemployment in Latin America and the Caribbean", NBER Working Paper, $\mathrm{N}^{\circ} 17274$, Cambridge, Massachusetts, National Bureau of Economic Research.

Banco Mundial (2012), The Labor Market Story Behind Latin America's Transformation, Washington, D.C.

Bensusán, Graciela (2008), "Regulaciones laborales, calidad de los empleos y modelos de inspección: México en el contexto latinoamericano" (LC/MEX/L.861), México, D.F., Sede subregional de la CEPAL en México.

(coord.) (2006), Diseño legal y desempeño real: Instituciones laborales en América Latina, México, D.F., Cámara de Diputados/Universidad Autónoma Metropolitana.

Berg, Janine y David Kucera (2008), "Labour institutions in the developing world: historical and theoretical perspectives", In Defence of Labour Market Institutions. Cultivating Justice in the Developing World, Janine Berg y David Kucera (eds.), Basingstoke, Palgrave MacMillan.

Berman, Eli, John Bound y Zvi Griliches (1994), "Changes in the demand for skilled labor within U.S. manfacturing: evidence from the Annual Survey of Manufactures", The Quarterly Journal of Economics, vol. 109, $\mathrm{N}^{\circ}$ 2, Oxford University Press, mayo.

BID (Banco Interamericano de Desarrollo) (2003), Se buscan buenos empleos. Los mercados laborales de América Latina, Washington, D.C.

(1997), Progreso Económico y Social en América Latina. Informe 1997, Washington, D.C.

Bosch, Mariano, M. Belén Cobacho y Carmen Pagés (2012), "Taking stock of nine years of implementation of Seguro Popular in Mexico", Technical Notes, $\mathrm{N}^{\circ}$ IDB-TN-442, Washington, D.C., Banco Interamericano de Desarrollo.

Bosch, Mariano y Marco Manacorda (2010), "Minimum wages and earnings inequality in urban Mexico", American Economic Journal: Applied Economics, vol. 2, $\mathrm{N}^{\circ} 4$, Nashville, Tennessee, American Economic Association.

CEPAL (Comisión Económica para América Latina y el Caribe) (2014a), Balance Preliminar de las Economías de América Latina y el Caribe 2013 (LC/G.2581-P), Santiago de Chile. Publicación de las Naciones Unidas, $\mathrm{N}^{\circ}$ de venta: S.14.II.G.2. (2014b), Estudio Económico de América Latina y el Caribe 2014 (LC/G.2619-P), Santiago de Chile. Publicación de las Naciones Unidas, $\mathrm{N}^{\circ}$ de venta: S.14.II.G.3.

(2014c), Pactos para la igualdad. Hacia un futuro sostenible (LC/G.2586(SES.35/3)), Santiago de Chile.

(2013), Panorama Social de América Latina 2013 (LC/G.2580), Santiago de Chile. Publicación de las Naciones Unidas, $\mathrm{N}^{\circ}$ de venta: S.14.II.G.6.

(2012), Panorama Social de América Latina 2011 (LC/ G.2514-P), Santiago de Chile. Publicación de las Naciones Unidas, $\mathrm{N}^{\circ}$ de venta: S.12.II.G.6.

(2010), La hora de la igualdad: Brechas por cerrar, caminos por abrir (LC/G.2432(SES.33/3)), Santiago de Chile.

(2007), "Progreso técnico y cambio estructural en América Latina", Documento de Proyecto, $\mathrm{N}^{\circ} 136$ (LC/W.136), Santiago de Chile. (varios años), Estudio Económico de América Latina y el Caribe, Santiago de Chile.

CEPAL/OIT (Comisión Económica para América Latina y el Caribe/ Organización Internacional del Trabajo) (2013), "Crisis y recuperación del empleo juvenil", Coyuntura Laboral en América Latina y el Caribe, $\mathrm{N}^{\circ} 7$, Santiago de Chile, octubre.

(2012), "Productividad laboral y distribución", Coyuntura Laboral en América Latina y el Caribe, $\mathrm{N}^{\circ}$ 6, Santiago de Chile, mayo.

CEPAL/OIT/FaO (Comisión Económica para América Latina y el Caribe/Organización Internacional del Trabajo/Organización de las Naciones Unidas para la Alimentación y la Agricultura) (2012), Políticas de mercado de trabajo y pobreza rural en América Latina, Organización de las Naciones Unidas para la Alimentación y la Agricultura (FAO), Roma.

Cornia, Giovanni Andrea (2014), "Income inequality in Latin America. Recent decline and prospects for its further reduction", serie Macroeconomía del Desarrollo, N $^{\circ} 149$ (LC/L.3847), Santiago de Chile, Comisión Económica para América Latina y el Caribe (CEPAL).

Cortez, Willy W. (2001), "What is behind increasing wage inequality in Mexico?", World Development, vol. 29, N ${ }^{\circ} 11$, Amsterdam, Elsevier.

Cruces, Guillermo, Carolina García Domenech y Leonardo Gasparini (2012), "Inequality in education: evidence for Latin America”, Documento de Trabajo, $\mathrm{N}^{\circ} 135$, Centro de Estudios Distributivos, Laborales y Sociales (CEDLAS).

Eichhorst, Werner, Michael Feil y Christoph Braun (2008), "What have we learned? Assessing labor market institutions and indicators", IZA Discussion Papers, N 3470 , Bonn, Institute for the Study of Labour (IZA).

Fields, Gary (2004), A Guide to Multisector Labor Market Models, Washington, D.C., noviembre.

Fraile, Lydia (2009), "La experiencia neoliberal de América Latina. Políticas sociales y laborales desde el decenio de 1980", Revista Internacional del Trabajo, vol. 128, $\mathrm{N}^{\circ} 3$.

Freeman, Richard B. (2005), "Labor market institutions without blinders: the debate over flexibility and labor market performance", NBER Working Paper, $\mathrm{N}^{\circ}$ 11286, Cambridge, Massachusetts, National Bureau of Economic Research.

Gasparini, Leonardo y otros (2011), "Educational upgrading and returns to skills in Latin America. Evidence from a supplydemand framework, 1990-2010", Policy Research Working Paper, $\mathrm{N}^{\circ}$ 5921, Washington, D.C., Banco Mundial.

Infante, Ricardo (ed.) (2011), "El desarrollo inclusivo en América Latina y el Caribe. Ensayos sobre políticas de convergencia productiva para la igualdad", Libros de la CEPAL, $\mathrm{N}^{\circ} 112$ (LC/G.2500-P), Santiago de Chile, Comisión Económica para América Latina y el Caribe (CEPAL). Publicación de las Naciones Unidas, $\mathrm{N}^{\circ}$ de venta: S.11.II.G.56.

Kacef, Osvaldo y Rafael López-Monti (2010), "América Latina, del auge a la crisis: Desafíos de política macroeconómica”, Revista CEPAL, $\mathrm{N}^{\circ} 100$ (LC/G.2442-P), Santiago de Chile.

Keifman, Saúl N. y Roxana Maurizio (2012), "Changes in labour market conditions and policies. Their impact on wage inequality during the last decade", WIDER Working Papers, N $^{\circ} 2012 / 14$, Helsinki, Universidad de las Naciones Unidas/Instituto Mundial de Investigaciones de Economía del Desarrollo.

Klasen, Stephan, Thomas Otter y Carlos Villalobos Barría (2012), "The dynamics of inequality change in a highly dualistic economy: Honduras, 1991-2007", WIDER Working Papers, $N^{\circ}$ 2012/17, Helsinki, Universidad de las Naciones Unidas/ Instituto Mundial de Investigaciones de Economía del Desarrollo.

Lee, Sangheon y Deirdre McCann (2011), Regulating for Decent Work: New Directions in Labour Market Regulation, Ginebra, Organización Internacional del Trabajo (OIT) 
López-Calva, Luis F. y Nora Lustig (eds.) (2010), Declining Inequality in Latin America. A Decade of Progress?, Washington, D.C., Brookings Institution Press.

McMillan, Margaret S. y Dani Rodrik (2011), "Globalization, structural change and productivity growth", NBER Working Paper, $\mathrm{N}^{\circ} 17143$, Cambridge, Massachusetts, National Bureau of Economic Research.

Ocampo, José Antonio, Codrina Rada y Lance Taylor (2009), Growth and Policy in Developing Countries: A Structuralist Approach, Nueva York, Columbia University Press.

OIT (Organización Internacional del Trabajo) (2014), Experiencias recientes de formalización en países de América Latina y el Caribe, Lima, Oficina Regional de la oIT para América Latina y el Caribe.

(2013), "Key Indicators of the Labour Market (KILM)", octava edición [en línea] http://www.ilo.org/empelm/what/ WCMS_114240/lang--en/index.htm.

(2009), Informe sobre el trabajo en el mundo 2008. Desigualdades de renta en la era de la finanza global, Ginebra. (varios años), Panorama Laboral de América Latina y el Caribe, Lima, Oficina Regional para América Latina y el Caribe.

Pagés, Carmen, Gaëlle Pierre y Stefano Scarpetta (2009), Job Creation in Latin America and the Caribbean. Recent Trends and Policy Challenges, Washington, D.C., Banco Mundial.

Perry, Guillermo E. y otros (2007), Informality: Exit and Exclusion, Washington, D.C., Banco Mundial.

Rodrik, Dani (2013), "The past, present, and future of economic growth", Working Paper, $\mathrm{N}^{\circ} 1$, Global Citizen Foundation, junio.
Ros, Jaime (2011), "La productividad y el desarrollo en América Latina: Dos interpretaciones", Economía UNAM, vol. 8, № 23, México, D.F., Universidad Nacional Autónoma de México (UNAM).

Tokman, Víctor (1987), "El sector informal: Quince años después", Documento de Trabajo, $\mathrm{N}^{\circ} 316$, Santiago de Chile, Programa Regional del Empleo para América Latina y el Caribe (PREALC).

Vega Ruiz, María Luz (2005), La reforma laboral en América Latina: 15 años después, Lima, Oficina Regional de la oIT para América Latina y el Caribe.

Weller, Jürgen (2012), "Crecimiento, empleo y distribución de ingresos en América Latina", serie Macroeconomía del Desarrollo, $\mathrm{N}^{\circ} 122$ (LC/L.3516), Santiago de Chile, Comisión Económica para América Latina y el Caribe (CEPAL).

(2009), "Avances y retos para el perfeccionamiento de la institucionalidad laboral en América Latina", El nuevo escenario laboral latinoamericano. Regulación, protección y políticas activas en los mercados de trabajo, Jürgen Weller (ed.), Buenos Aires, Siglo XXI Editores.

(2000), Reformas económicas, crecimiento y empleo: Los mercados de trabajo en América Latina, Santiago de Chile, Comisión Económica para América Latina y el Caribe (CEPAL)/ Fondo de Cultura Económica.

Weller, Jürgen y Cornelia Kaldewei (2013), "Empleo, crecimiento sostenible e igualdad", serie Macroeconomía del Desarrollo, $\mathrm{N}^{\circ} 145$ (LC/L.3743), Santiago de Chile, Comisión Económica para América Latina y el Caribe (CEPAL).

Weller, Jürgen y Claudia Roethlisberger (2011), "La calidad del empleo en América Latina", serie Macroeconomía del Desarrollo, $\mathrm{N}^{\circ} 110$ (LC/L.3320-P), Santiago de Chile, Comisión Económica para América Latina y el Caribe (CEPAL). Publicación de las Naciones Unidas, $\mathrm{N}^{\circ}$ de venta: S.11.II.G.39. 